\title{
Existe Bolha no Mercado Imobiliário Brasileiro?
}

\author{
Mário Jorge Mendonça* \\ Adolfo Sachsida**
}

\begin{abstract}
Resumo: Este artigo avalia a possibilidade de existência de "bolha" especulativa no mercado imobiliário brasileiro. De maneira geral, os resultados apontam para a possibilidade concreta de existência de uma bolha no mercado de imóveis no Brasil. A Escola Austríaca de Economia, reforçada por técnicas estatísticas, fornece uma base teórica sólida para apontar o governo federal, por meio de suas políticas fiscais e de estímulo ao crédito, como o principal responsável pelo surgimento desta bolha.
\end{abstract}

Palavras-chave: Bolha Imobiliária, Escola Austríaca, VAR Estrutural, Condição da Política Fiscal, Projeção Condicional.

\section{Is There a Bubble in Brazilian Real State Market}

\begin{abstract}
This article verifies the occurrence of a real estate bubble in the Brazilian economy. Overall, our results suggest the existence of a bubble in the real estate sector of the economy. The Austrian School of economics provides a solid explanation to this phenomenon, which are reinforced by statistical techniques, suggesting the Federal government, with equivocate fiscal and monetary policy, as the main responsible for the creation of this problem.
\end{abstract}

Keywords: Real Estate Bubble, Austrian School, VAR Model, Stance of Fiscal Policy. Conditional Planning.

Classificação JEL: E32, R38.

\begin{abstract}
" Mário Jorge Mendonça é Técnico de Planejamento e Pesquisa do Instituto de Pesquisa Econômica Aplicada (IPEA) desde 1997. Cursou a graduação no Instituto Metodista Bennett (IMB), o mestrado em Economia pela Universidade Federal Fluminense (UFF) e o PhD em Economia pela École des Hautes Études en Sciences Sociales (EHESS). Foi professor substituto de Economia na UFF. Seus principais temas de pesquisas são: aplicação do modelo fatorial dinâmico para previsão de arrecadação de impostos, estimação da função de reação fiscal com mudança de regime, estimação do modelo VAR com identificação agnóstica para medir impactos das políticas fiscal e monetária, uso do método de projeção condicional para avaliar a condição da política fiscal. Também possui experiência nas áreas de economia do meio ambiente e economia do trabalho. É autor de inúmeros artigos publicados em diferentes revistas acadêmicas, bem como de capítulos em livros.

mario.mendonça@ipea.gov.br
\end{abstract}

** Adolfo Sachsida é pesquisador da Diretoria de Macroeconomia do Instituto de Pesquisa Econômica Aplicada (IPEA). Cursou o mestrado e o doutorado em Economia na Universidade de Brasília (UnB), além de receber o pós-doutorado pela University of Alabama. Lecionou Economia na Universidade Católica de Brasília (UCB) e na University of Texas - Pan American. Foi consultor short-term do Banco Mundial para Angola. A convite da JICA visitou o Japão para um intercâmbio com experts japoneses sobre modelagem macroeconômica. Tem experiência na área de Macroeconomia, com ênfase em Modelos Econométricos. Sua principal área de pesquisa refere-se ao uso de modelos econométricos para a resolução de questões econômicas. Publicou vários artigos nacional e internacionalmente, sendo considerado um dos pesquisadores brasileiros mais produtivos na área de economia. Atualmente esta pesquisando sobre: 1) A qualidade da política fiscal e monetária no Brasil; e 2) Fatores determinantes da violência urbana. sachsida@hotmail.com 
O presente estudo tem por objetivo avaliar a possibilidade de existência de "bolha" especulativa no mercado imobiliário brasileiro. Tal possibilidade tem sido levantada pela imprensa e por acadêmicos, em virtude das diversas notícias divulgadas acerca de elevação significativa dos preços dos imóveis. Atualmente, parecem existir fortes indícios de que o setor imobiliário se encontra fortemente aquecido no Brasil. Isso pode ser visto pelo número de novos lançamentos, e pelo vigoroso crescimento do preço de venda dos imóveis visto nos últimos anos.

De janeiro de 2010 a março de 2012, houve uma variação de $43 \%$ no preço médio de venda dos imóveis em todo o Brasil ${ }^{1}$. Das regiões consideradas, a cidade do Rio de Janeiro foi aquela que apresentou a maior valorização, seguida pela cidade de São Paulo. No Rio de Janeiro e em São Paulo, o preço de venda dos imóveis teve variação, entre janeiro de 2008 a março de 2012, de 168\% e $132 \%{ }^{2}$, respectivamente. Tomando apenas o período de janeiro de 2010 a março de 2012, a variação do preço do imóvel no Rio de Janeiro foi 58,86\% enquanto em São Paulo a variação ficou em 43,16\%. Concomitantemente, ocorreu no mesmo período um vigoroso aumento do estoque de crédito imobiliário, que mostrou variação de $130 \%$ em termos reais no mesmo período.

Muitos motivos podem ser apontados para explicar o boom imobiliário presenciado nos últimos anos. A estabilidade de preços, a queda na taxa de juros, a expansão do crédito direcionado, além dos programas de obras públicas são as explicações mais recorrentes para este fenômeno. Com a inflação controlada, a economia pode sentir os efeitos benéficos da estabilização. A queda da taxa de juros, por sua vez, diminui o custo do financiamento, fator fundamental neste mercado, tendo em vista que a grande parte das tran-

\footnotetext{
${ }^{1}$ Cálculo com base no índice ZAP-FIPE.

${ }^{2} \mathrm{O}$ IBOVESPA variou no mesmo período em apenas $8.4 \%$ enquanto o CDI apresentou rendimento de $52,3 \%$. A taxa de inflação medida pelo IPCA no período foi de $25 \%$.
}

sações imobiliárias é levada a cabo com financiamentos de longo prazo.

Também devemos ressaltar que o crescimento da economia, com o consequente aquecimento do mercado de trabalho, elevou a renda do trabalhador, facilitando a este o acesso ao mercado imobiliário. Outro detalhe importante se refere às mudanças na legislação que tornaram o investimento no setor mais seguro. Evidentemente, as políticas públicas do governo específicas para este setor também ajudaram a aquecer o mercado imobiliário. Tais ações públicas têm como objetivo facilitar o acesso à casa própria a grupos específicos da população, sobretudo aos grupos pertencentes ao extrato de baixa renda ${ }^{3}$. Além disso, o programa de obras públicas que tem como propósito modernizar e dinamizar algumas cidades para atender os eventos mundiais com a Copa do Mundo em 2014, e as Olimpíadas no Rio de Janeiro em 2016, vem contribuindo para a valorização dos imóveis.

No entanto, tendo em vista esse vertiginoso crescimento no preço e na crescente expansão da oferta de imóveis no Brasil, alguns analistas têm chamado atenção para a possível existência de uma bolha no mercado imobiliário. Segundo eles, o preço dos imóveis residenciais e comerciais têm crescido além do que pode ser explicado pelos "fundamentos" que deveriam reger o movimento de preços neste setor como em qualquer outro. Tal apreensão tem relação com a crise de proporção catastrófica que ocorreu na economia norte-americana em 2008, cujo estopim foi o setor imobiliário, e mais recentemente com os casos de Espanha, Portugal e Grécia. Sendo assim, na primeira seção, apresentaremos alguns dos argumentos mais comumente usados a favor da existência de bolha imobiliária no Brasil e mostraremos que nenhum deles possui

\footnotetext{
${ }^{3} \mathrm{O}$ projeto Minha Casa Minha Vida tem como foco as famílias que possuem renda de zero a três salários mínimos. Não obstante, houve redirecionamento dos recursos da poupança para o sistema de financiamento da casa própria. A medida, aprovada pelo Conselho Monetário Nacional, incrementou em R \$ 1,6 bilhão os recursos para o setor.
} 
consistência teórica para servir de base para qualquer argumentação mais robusta.

$\mathrm{Na}$ verdade, muito embora seja comum se verificar o aparecimento do termo "bolha" especulativa, tanto na literatura acadêmica como na impressa em geral, o conceito de bolha especulativa no sentido usado na literatura "mainstream" está longe de ser algo trivial. De fato, a ideia que comumente aparece associada à existência de bolha é algo atrelado a um comportamento irracional dos agentes econômicos que acreditam que o preço irá crescer indefinidamente, ou pelo menos se comportará assim num horizonte temporal bem longo. Tão complicado como conceituar uma bolha especulativa é a sua verificação empírica nesse tipo de abordagem. No caso presente, isso se torna impraticável tendo em vista preponderantemente a insuficiência de dados de preço de venda e aluguel para o mercado imobiliário no Brasil. Por esse motivo e também por não considerar apropriado o modo "mainstream" de definir o conceito de bolha, usaremos neste estudo uma definição alternativa nomeada por "austríaca", cuja base teórica está associada à Escola Austríaca de Economia. O que foi dito neste parágrafo é o objeto de análise na segunda seção do trabalho.

Como será visto, de acordo com a perspectiva Austríaca, uma bolha de mercado não surge por força de um comportamento irracional, e sim por consequência de um sinal exogenamente criado que faz com que os agentes direcionem erroneamente os investimentos num determinado segmento da economia, fazendo com que os preços desse mercado sigam uma trajetória fortemente ascendente. Tal elevação não poderá se estender indefinidamente, fazendo com que os agentes em algum instante percebam que o retorno sobre o investimento se situa aquém do esperado. É o instante em que se dá o ponto de ruptura. Neste momento, haverá uma revisão dos projetos, sendo que uma perda acentuada de capital se configura como algo inerente ao processo. Para entender como isso funciona, a terceira seção faz uma apresentação da Teoria Austríaca dos Ciclos Econômicos (TACE).
Mais precisamente, a TACE foi elaborada com o intuito de explicar por que numa economia ocorrem fases de expansão e recessão, ou mesmo uma depressão. Contudo, como será visto, muito do que acontece hoje no mercado imobiliário pode ser explicado com base nos preceitos dessa teoria. Diferente da perspectiva "mainstream" sobre bolha especulativa, a TACE nos permite obter meios para verificar, pelo menos indiretamente, a possibilidade de existência de bolha no mercado imobiliário.

Com base na teoria do ciclo de negócios, proposta pela Escola Austríaca (EA), é que, na quarta seção, introduzimos uma sequência de procedimentos empíricos com objetivo de checar se existe evidência de bolha especulativa no mercado imobiliário brasileiro. Inicialmente, é feita uma análise qualitativa acerca do comportamento de algumas variáveis relacionadas à construção civil e ao mercado imobiliário (produto industrial da construção civil, preço de venda e aluguel dos imóveis, evolução do crédito bancário, custo da construção, etc) com o intuito de verificar se existe alguma evidência de descolamento da evolução dessas variáveis em relação com o restante da economia. A seguir, empregamos procedimentos estatísticos mais consistentes para checar o que acontece no mercado imobiliário tanto a nível microeconômico como macroeconômico.

A análise microeconômica é feita com base na análise econométrica, no sentido de checar se o preço corrente dos imóveis responde aos seus fundamentos. Além disso, checa-se a existência de pressão sobre a estrutura de custo dos imóveis. A abordagem empírica sob a ótica macroeconômica se baseia em dois procedimentos. O primeiro deles visa determinar o estado da política fiscal no Brasil. No nosso caso, uma medida quantitativa do estado da política fiscal é útil por permitir saber se a condição fiscal tem exercido pressão sobre o produto da economia. A importância disso decorre do fato de que se o produto se situar acima do potencial por efeito da política fiscal, isso poderá se refletir numa elevação da inflação. Se isso acontecer, a taxa de juros terá que sofrer ajuste 
para cima em algum momento. $\mathrm{O}$ aumento da taxa de juros pode ter impacto significativo no mercado imobiliário pelo seu efeito sobre a elevação do custo do financiamento. Neste caso, um teste subsequente é feito com base na metodologia VAR estrutural com o propósito de checar o efeito de um choque contracionista de política monetária sobre variáveis relacionadas ao mercado imobiliário, tais como o produto industrial da construção civil e o fluxo de crédito imobiliário.

\section{I - Prós e Contras Acerca DA ExistênCIA DE Bolha IMOBILIÁRIA NO BRASIL}

Vejamos alguns dos argumentos sobre bolhas imobiliárias levantados por estudiosos do assunto. De acordo com João da Rocha Lima Jr. a evidência de bolha se dá pelo fato de "que o preço dos imóveis residenciais está acima do seu valor justo - valor não é atributo de qualquer bem, mas o preço justo equivale a um valor justo"s. Seguindo o mesmo raciocínio, Lima Júnior acrescenta que o preço justo deve cobrir os custos de produção, bem como conter uma margem para cobertura das incertezas. Acrescenta ainda:

Com os preços atuais, se contarmos os custos, as margens, a estrutura tradicional de funding, com financiamento à produção no $\mathrm{SFH}^{5}$, encontraremos taxas de retorno desequilibradas para a atratividade do real estate, nos padrões reconhecidos no mercado brasileiro [...] Se os preços estão acima do preço justo, há um valor sem lastro que está sendo comprado pelo mercado nesta conjuntura ${ }^{6}$.

A falácia dessa argumentação decorre do fato de que, como é ponto pacífico na teoria econômica, ovalor de um bem decorre da utili-

\footnotetext{
${ }^{4}$ LIMA JR., J. R. Alerta de Bolha. Carta do NRE-POLI, No. 25-11 (2011), Núcleo de Real State, USP.

${ }^{5}$ Sistema Financeiro da Habitação.

${ }^{6}$ LIMA JR. Alerta de Bolha.
}

dade marginal que os indivíduos denotam a ele, sendo que a utilidade é definida pelas preferências dos agentes. Isto é, o preço de mercado é determinado pelo valor subjetivo que as pessoas têm pelo bem. Decorre daí que a estrutura de custos de um produto está indiretamente relacionada a quanto os indivíduos aceitam pagar pelo produto. Fatores de produção usados na confecção de um bem altamente valorado tendem a se tornar mais caros e vice-versa. Desse modo, o preço de um fator de produção deve refletir sua contribuição marginal ao valor do produto até o ponto onde não exista mais possibilidade de arbitragem ${ }^{7}$. Assim, a ordem de causalidade é de cima para baixo, ou seja, a valoração de um bem é o que determina seu custo e, não o contrário. No caso dos imóveis, pode estar acontecendo que, por um motivo ou outro, como por exemplo, uma mudança na estrutura de preferência, os agentes estão atribuindo maior valor aos imóveis elevando a demanda e os preços como consequência. Daí, o diferencial entre o preço e o custo está propiciando uma expectativa de alta margem de lucro que irá ser gradualmente eliminada desde que não existam restrições à ampliação da oferta. Afinal, existe uma defasagem de tempo para que a estrutura de custo acom-

7 Em termos genéricos, dentro da perspectiva da Escola Austríaca, o preço de um fator de produção corresponde em equilíbrio à contribuição que uma unidade a mais desse fator irá adicionar ao produto descontado, ou seja, o preço do fator deve ser igual ao valor presente do produto marginal. Esse é o ponto onde o lucro alcança o ótimo. Suponhamos que preço unitário do fator esteja abaixo da receita marginal que o fator adicionaria ao negócio. Neste caso existe margem para o empresário aumentar o uso desse fator na confecção do seu produto. Desse modo, a demanda pelo fator aumenta e, por consequência, o seu preço até que o equilíbrio seja alcançado (ROTHBARD, M. Man, Economy and State. Auburn: Ludwig von Mises Institute, 1993). O calcanhar de Aquiles da teoria que tenta justificar o valor com base no custo é não explicar de onde se origina, por sua vez, o valor de troca dos fatores de produção (WICKSELL, K. Lições de Economia Política. Trad. Maria Beatriz de Albuquerque David. São Paulo: Abril Cultural, 1983. Coleção Os Economistas). 
panhe essa maior valoração, que com o passar do tempo irá ser diminuída, e a lucratividade neste setor acompanhará aquela que existe no restante da economia.

Outro motivo usado para antever a ocorrência de bolha imobiliária reside no fato de que existe atualmente um descompasso entre o preço do imóvel e o preço do aluguel. Portanto, não valeria a pena comprar um imóvel tendo em vista o baixo preço do aluguel. Segundo este raciocínio, o investimento em imóvel não apresenta retorno compatível com o desembolso realizado. $\mathrm{O}$ contraponto a esse argumento pode ser colocado da seguinte forma. Tal como qualquer ativo, a decisão acerca de um investimento tem como base a seguinte equação (1), onde $q_{t}$ representa o preço do ativo em $t, d_{t+1}$ o rendimento do ativo, $r_{t}$ a taxa de desconto, que pode ser aquela que ofereceria um retorno livre de risco ou algum investimento alternativo, e $E_{t}$, a expectativa futura formada com base num conjunto de informação $I_{t}$ disponível no período $t$. Pode ser visto, pela equação (1) que o valor do ativo depende não apenas do seu retorno (rendimento), mas também da valorização, $q_{t+1}$, da taxa de juros e das expectativas.

$$
q_{t}=\frac{E\left[q_{t+1}+d_{t+1} \mid I_{t}\right]}{r_{t}}
$$

Portanto, de acordo com (1) o fator importante na tomada de decisão se concentra naquilo que os indivíduos acreditam que acontecerá, e não exatamente no que está ocorrendo no tempo presente. Também é fácil perceber que a expectativa de valorização é tão importante quanto o rendimento do ativo, ponto que foi desconsiderado no exemplo acima. Pode-se argumentar que o preço dos imóveis já esteja tão elevado a ponto que uma valorização futura seja improvável de acontecer. De fato, essa é uma justificativa que tem sido levantada para apontar possíveis problemas no mercado imobiliário. Contudo, deve-se perceber que o preço do aluguel pode também se elevar e de fato, parece que é o que ocorre pelo menos com maior intensidade da cidade do Rio de Janeiro nos últimos dois anos.
Outra questão importante que a argumentação colocada acima não leva em consideração é que a própria taxa de juros pode variar. Se a taxa de juros diminui, o que vem acontecendo recorrentemente com a economia brasileira, o custo de oportunidade diminui. Disso decorre a possibilidade de ganho de arbitragem, dado que mantido o resto constante, o valor presente esperado de ganho, lado direito da equação (1) aumenta frente ao capital investido na compra do imóvel. O impacto da taxa de juros na demanda por imóvel é algo que já é de conhecimento há muito tempo. A taxa de juros se encontra entre as variáveis que possuem maior impacto sobre o setor imobiliário. Uma mudança nesta pode alterar significativamente a situação do mutuário já que o termo de um contrato de financiamento pode se estender até trinta anos. Portanto, também pouco pode ser dito sobre a verdadeira situação no mercado imobiliário por que não se sabe quantificar o efeito de uma variação da taxa de juros sobre a função de demanda por imóveis. Assim, o simples fato dos preços dos imóveis terem subido muito nos últimos anos pode ser simplesmente o efeito da queda da taxa de juros devido à estabilização da economia.

\section{II - DefiniçÃo de Bolha: "Mainstream" versus "Austríaca"}

\section{II.1 - Abordagem "Mainstream"}

A definição de bolha de acordo com a abordagem "mainstream" aparece bem descrita em um artigo de Joseph Stiglitz: se a razão pela qual o preço de um ativo decorre apenas da crença de que seu preço de venda será maior no futuro, quando os fundamentos não parecem justificar isso, então uma bolha existe $^{8}$. Neste caso, a causa básica de movimentos de preços é determinada apenas pela expectativa auto-realizável da própria

\footnotetext{
${ }^{8}$ STIGLITZ, J. E. Symposium on Bubbles. Journal of
} Economic Perspectives, Vol. 4, No. 2 (Spring 1990): 13-18. 
variação de preços, levando a uma espiral de elevação continua até que em decorrência de algum fator a bolha estoure. Um dos axiomas da teoria das expectativas racionais é que os agentes não cometem erros sistemáticos. Neste sentido, a existência de bolhas impõe uma restrição à ideia de que o mercado age sempre de forma eficiente na alocação dos recursos, pois a formação do preço de um ativo estaria sendo imposta apenas pelas expectativas que se "auto-realizam", independente dos fundamentos de mercado. Para entender isso vamos reescrever a equação (1) da seguinte forma

$$
q_{t}=\frac{E\left[q_{t+1} \mid I_{t}\right]}{r_{t}}+\frac{d_{t}}{r_{t}}
$$

Tomando a taxa de desconto constante de modo que $a=1 / r$, temos:

$$
q_{t}=a E\left[q_{t+1} \mid I_{t}\right]+a d_{t}
$$

Resolvendo recursivamente e usando a lei das expectativas iteradas ${ }^{9}$ temos:

$$
q_{t}=\sum_{i=0}^{T} a^{i} E\left[d_{t+i} \mid I_{t}\right]+a^{T+1} E\left[q_{t+T+1} \mid I_{t}\right] \text { (3) }
$$

Aqui assumimos que o segundo termo de (3) converge para zero. Então(,) se

$$
\begin{array}{r}
\lim _{T \rightarrow \infty} a^{T+1} E\left[q_{t+T+1} \mid I_{t}\right]=0 \text {, segue: } \\
q_{t}=\sum_{i=0}^{\infty} a^{i} E\left[d_{t+i} \mid I_{t}\right]
\end{array}
$$

A equação (4) implica que o preço de um ativo é igual ao valor presente descontado de seus rendimentos futuros. Embora a equação (4) seja solução de $\left(1^{\prime}\right)$, ela não é a única solução. Ela foi derivada impondo a condição de transversalidade de que o preço do ativo não exploda. Naturalmente, esta hipótese pode ser relaxada de modo que $\left(1^{\prime}\right)$ possa admitir várias soluções. Façamos, que $q_{t}=q_{t}^{*}+b_{t}$, vejamos que tipo de restrição deve ser imposto sobre $b_{t}$ de forma que $q_{t}$ seja também uma solução para $\left(1^{\prime}\right)$. Se $q_{t}=q_{t}^{*}+b_{t}$, então

\footnotetext{
${ }^{9}$ Esta lei se define da seguinte forma, $E\left[E\left[x \mid I_{t+1}\right] \mid I_{t}\right]=E\left[x \mid I_{t}\right]$
}

$E\left[q_{t+1} \mid I_{t}\right]=E\left[q_{t+1}^{*} \mid I_{t}\right]+E\left[b_{t+1} \mid I_{t}\right]$. Substituindo estas duas equações em $\left(1^{\prime}\right)$, implica que

$$
q_{t}^{*}+b_{t}=a E\left[q_{t+1}^{*} \mid I_{t}\right]+a E\left[b_{t+1} \mid I_{t}\right]
$$

Pela definição de $q_{t}^{*}$ em (4), temos que $b_{t}=a E\left[b_{t+1} \mid I_{t}\right]$. Então para qualquer $b_{t}$ que satisfaz (5), $q_{t}=q_{t}^{*}+b_{t}$ é uma solução de $\left(1^{\prime}\right)$. Olivier Jean Blanchard e Stanley Fischer apresentam alguns processos distintos que $b_{t}$ pode seguir e que se enquadram dentro da noção popularmente associada à bolha especulativa ${ }^{10}$. Por essa razão, enquanto $q_{t}^{*}$ é chamada de solução fundamental, $b_{t}$ é denominada de bolha.

Blanchard e Fischer enumeram algumas situações onde o próprio mercado se incumbiria de eliminar a existência de bolhas ${ }^{11}$. Por exemplo, caso um ativo pudesse ser posto de lado sem custo, não haveria possiblidade de existir bolha negativa. Também um ativo real que possua um substituto com oferta elástica, a hipótese de bolha estaria igualmente descartada. Mesmo no mercado de ações, a elevação contínua do preço das ações motivaria o mercado a ofertar mais deste ativo. Admitindo o fato que a demanda não pode se estender indefinidamente, a valorização das ações tenderia a arrefecer eliminando a ocorrência de bolha. Portanto, nesse tipo de abordagem, o descolamento do preço do ativo em relação aos seus fundamentos seria mais provável de ocorrer nos mercados onde a informação acerca dos fundamentos seja de difícil obtenção. Por exemplo, em mercados específicos tais como o mercado de artes, de ouro, ou de moedas estrangeiras.

Obviamente, o aparato descrito acima é apenas uma definição, e não dá indicações de porque tal comportamento se justifica. Como ele tem pouca base em fundamentação econômica, sempre houve dificuldade em interpretar o porquê de uma bolha existir, ou então de se endereçar a questão em termos empíricos com

${ }^{10}$ BLANCHARD, Olivier Jean \& FISCHER, Stanley. Lectures on Macroeconomics. Cambridge: MIT Press, 1989.

${ }^{11}$ Idem, Ibidem. 
objetivo de predizer sua ocorrência. Existem diversas dificuldades econométricas para se detectar a existência de bolhas no modelo acima descrito. Inicialmente, as expectativas não são observadas. Em segundo lugar, muitos testes não apresentam um procedimento livre de crítica para tratar a taxa de desconto (geralmente ela é tomada como sendo constante). Terceiro, não há como diferenciar se o descolamento do preço do ativo em relação aos fundamentos advém da ocorrência de uma bolha ou pelo fato de que os próprios fundamentos foram mal especificados ${ }^{12}$.

Os primeiros testes visando detectar a existência de bolha neste tipo de modelagem datam dos estudos de Robert Shiller ${ }^{13}$, de Stephen F. LeRoy e Richard D. Porter ${ }^{14}$, e de Kenneth D. West ${ }^{15}$ na década de 1980. Inicialmente, os testes procuravam detectar bolhas de qualquer tipo, sem especificar a sua natureza. Basicamente estes testes centravam-se em determinar limites para a variância, considerando o preço ex post do ativo, $p_{t}^{\prime}$, e o valor presente de seus dividendos. O teste de Shiller adota o preço presente da ação como sendo o melhor previsor do valor futuro descontado dos dividendos. Definindo o preço ex post como

$$
p_{t}^{\prime}=\sum_{i=0}^{\infty} a^{i+1} d_{t+i}
$$

${ }^{12}$ FLOOD, R. P \& GARBER, P. M. Market Fundamentals versus Price Level Bubbles: The First Tests. Journal of Political Economy, Vol. 88, No. 4 (1980): 74570; HAMILTON, J. D. \& WHITEMAN, C. H. The Observable Implications of Self-Fulfilling Expectations. Journal of Monetary Economics, 16 (1985): 353-73; CASELLA, A. (1989). Testing for Rational Bubbles with Exogenous or Endogenous Fundamentals. Journal of Monetary Economics, 24: 109-22.

13 SHILLER, R. Do Stock Prices Move Too Much to be Justified by Subsequent Changes in Dividends? American Economic Review, 71 (June 1981): 421-36.

${ }^{14}$ LEROY, S. F. \& PORTER, R. D. The Present-Value Relation: Tests Based on Implied Variance Bounds. Econometrica, 49 (May 1981): 555-74.

15 WEST, K. D. A Specification Test for Speculative Bubbles. The Quarterly Journal of Economics, 102 (August 1987): 553-80.
Temos que $p_{t}^{\prime}=p_{t}+u_{t}$, onde $E\left[u_{t} \mid I_{t}\right]=0$.

Supondo que a $p_{t}^{\prime}=p_{t}+u_{t}$ seja não correlacionado com o preço corrente temos que $V\left(p_{t}^{\prime}\right)=V\left(p_{t}\right)+V\left(u_{t}\right)$, onde $V$ representa a variância. Isso implica que $V\left(p_{t}^{\prime}\right) \geq V\left(p_{t}\right)$, de modo que a variância do preço ex post deve ser exceder ao preço observado. Assim, desde que $p_{t}$ é um previsor de $p_{t}^{\prime}$ deve-se mover menos que esse. A série de $p_{t}^{\prime}$ tomando a seguinte equação como base

$$
p_{t}^{\prime}=\sum_{i=0}^{T} a^{i+1} d_{t+i}+a^{T-1} p_{T}^{\prime}
$$

Onde $T$ representa $o$ final da amostra.

Robert Shiller constrói $p_{t}^{\prime}$ tomando a média amostral de $p_{t}$, sendo que os desvios de $p_{t}^{\prime} \mathrm{e}$ $p_{t}$ em relação à tendência determinística são usados para construir as variâncias dessas duas variáveis ${ }^{16}$. $\mathrm{O}$ teste de Shiller gera somente estimativas pontuais para a variância de modo que sua significância estatística não pode ser testada.

Tanto Jean Tirole ${ }^{17}$ quanto Olivier Jean Blanchard e Mark W. Watson ${ }^{18}$ sugeriram que o limite da variância pudesse ser violado devido à presença de bolhas. Sendo assim, a primeira linha de ataque para o teste de Shiller recai sobre as propriedades das distribuições estatísticas advindas do teste ${ }^{19}$. Contudo, devemos ressaltar que, embora uma violação do limite da variância construída possa ser devido à presença de bolhas, esses testes têm variados problemas para sua implementação, tornando-os inaptos a detectar a presença de bolhas. Marjorie A. Flavin mostrou que, em relação à

${ }^{16}$ SHILLER. Do Stock Prices Move Too Much to be Justified by Subsequent Changes in Dividends?

17 TIROLE, J. Asset Bubbles and Overlapping Generations. Econometrica, 53 (1985): 1499-528.

${ }^{18}$ BLANCHARD, O. J. \& WATSON, M. W. Bubbles, Rational Expectations and Financial Markets. NBER Working Paper, No. 945 (1982).

${ }^{19}$ SHILLER. Do Stock Prices Move Too Much to be Justified by Subsequent Changes in Dividends? 
rejeição da hipótese de bolha para pequenas amostras, usar o preço médio para representar o preço terminal ex post viesa o teste ${ }^{20}$. Allan W. Kleidon discute um ponto mais sutil: as variâncias em questão são variâncias de corte transversal num ponto no tempo, mas na estimação as variâncias usadas são construídas por séries temporais ${ }^{21}$. Ele mostra que o dado elaborado do modelo do valor presente líquido viola a hipótese de variância limitada quando séries não estacionárias são usadas. Terry A. Marsch e Robert C. Merton igualmente fornecem um exemplo interessante da inabilidade do teste de variância limitada quando os dividendos e o preço das ações são não estacionários ${ }^{22}$.

Vários testes interessantes foram subsequentemente desenvolvidos para verificar a hipótese de bolha especulativa ${ }^{23}$. Contudo, numa resenha acerca dos vários tipos de metodologias econométricas empregadas para testar a existência de bolha racional, Refet $S$. Gürkaynak mostra que apesar dos avanços recentes nesta área, a detecção econométrica de bolhas no preço dos bens não pode ser obtida

${ }^{20}$ FLAVIN, M. A. Excess Volatility in the Financial Markets: A Reassessment of the Empirical Evidence. Journal of Political Economy, 91(December 1983): 929-56

${ }^{21}$ KLEIDON, A. W. Variance Bounds Tests and Stock Price Valuation Models. Journal of Political Economy, 94 (October 1986): 953-1001.

${ }^{22}$ MARSH, T. A. \& MERTON, R. C. Dividend Variability and Variance Bounds Tests for the Rationality of Stock Market Prices. American Economic Review, 76 (June 1983): 483-98.

${ }^{23}$ WEST, K. D. Bubbles, Fads and Stock Price Volatility Tests: A Partial Evaluation. Journal of Finance, 43 (1988): 639-56; CAMPBELL, John \& SHILLER Robert. Stock Prices, Earnings, and Expected Dividends. Journal of Finance, 43 (July 1988): 661-76; CAMPBELL, John \& SHILLER Robert. The Dividend-Price Ratio and Expectations of Future Dividends and Discount Factors. Review of Financial Studies, Vol. 1, No. 3 (1989): 195228; DIBA, B. \& GROSSMAN, H. On the Inception of Rational Bubbles. Quarterly Journal of Economics, 87 (August 1987): 697-700; EVANS, G. Pitfalls in Testing for Explosive Bubbles in Asset Prices. American Economic Review, 31 (September, 1991): 922-30. com um grau de certeza satisfatório ${ }^{24}$. Entre os principais problemas econométricos destaca-se a incapacidade de se distinguir bolhas de um modelo com mudança de regime, ou então com quebra estrutural nos fundamentos, ou ainda com os problemas econométricos relacionados à inferência em pequenas amostras.

\section{I.2 - Abordagem "Austríaca"}

São diversas as dificuldades que surgem quanto ao emprego da abordagem descrita na seção anterior para tratar a questão da bolha especulativa. Primeiro, em relação à abordagem empírica, muitas questões são levantadas quanto à dificuldade do emprego de técnicas econométricas para detectar bolhas no preço dos ativos. Segundo, no caso que estamos tratando, existe ainda um complicador adicional referente à insuficiência de dados sobre preços de imóveis no Brasil. Em terceiro lugar, conforme bem salientou Blanchard e Fischer, a ocorrência de bolha deve se justificar mais em mercados propensos a problemas de informação, o que não parece ser o caso do mercado imobiliário ${ }^{25}$. Em quarto lugar, a própria definição de bolha, tal como está escrito na seção anterior, suscita controvérsia.

Peter M. Garber analisou três casos famosos usados como exemplos de bolha na literatura, e encontrou fortes indícios de que tal apelo para a existência de bolhas está longe de ser uma resposta convincente a esses três eventos $^{26}$. Em todos esses casos foi possível encontrar alterações nos fundamentos de mercado que justificaram as mudanças observadas no preço dos ativos, ou no estado de coisas da economia.

Por fim, admitir a ideia de bolha dentro da concepção "mainstream" é aceitar o fato

${ }^{24}$ GÜRKAYNAK, R. F. Econometric Tests of Asset Price Bubbles: Taking Stock. Washington: Federal Reserve Board, 2005.

25 BLANCHARD, O. \& FISCHER, S. Lectures on Macroeconomics.

${ }^{26}$ GARBER, P. M. Famous First Bubbles. Journal of Economic Perspectives, Vol. 4, No. 2 (Spring 1990): 35-54. 
de que, em certas situações diferentes das já previstas pela teoria econômica ${ }^{27}$, o mecanismo de preços falha em promover a sinalização correta para a alocação eficiente de recursos. Como se pode notar, o estudo sobre bolhas especulativas é permeado de dificuldades técnicas. Além disso, tais dificuldades se tornam maiores quando levamos em consideração os problemas estatísticos relacionados a pequenas amostras. Sendo assim, analisar a existência de uma bolha no mercado imobiliário brasileiro está longe de se constituir em uma tarefa trivial.

Para direcionar nossa pesquisa de maneira a ser possível contornar os problemas explicitados anteriormente, vamos elaborar nossa análise partindo de uma ideia simples: se os preços em determinado mercado se alteram, isso acontece por basicamente dois motivos. Primeiro, se ocorreu uma mudança nos fundamentos desse mercado (ou em mercados correlatos) que estariam levando a tal estado de coisas. Nesse sentido, as próprias forças de mercado conduziriam a um equilíbrio compatível com a nova ordenação.

Segundo, uma mudança de preço pode decorrer também devido à interferência do governo. Numa situação específica, onde o preço de um ativo parece se elevar indefinidamente sem base nos fundamentos de mercado, tal como se verifica no caso da bolha especulativa, partimos do pressuposto que algum sinal, ou incentivo, estaria induzindo os agentes a entrarem naquela empreitada. Sendo assim, o estouro da bolha evidencia, por definição, que erros de avaliação sistemáticos foram cometidos de modo generalizado.

Tendo em mente que o mercado oferece um treino para que os agentes econômicos possam aprimorar suas habilidades, no que se refere à gerência dos seus próprios negócios, e que boa parte dos mercados não apresenta problemas significativos de informação, então

\footnotetext{
${ }^{27}$ Em situações denominadas de "falhas de mercado", a literatura mainstream mostra que o mecanismo de preços resultante do mercado não conduz a uma alocação eficiente de recursos para a sociedade.
}

como explicar que erros de previsão sistemáticos foram cometidos por tão longo tempo e de forma generalizada? De outro modo, como explicar que indivíduos bem treinados se deixem iludir acerca das reais oportunidades de negócios? De acordo com a Escola Austríaca de Economia, o responsável por tais erros de julgamento são as políticas governamentais de interferência (a manipulação da taxa de juros, ou do direcionamento do crédito pelo governo, são exemplos de tais políticas). Para a Escola Austríaca, as políticas governamentais fazem com que os agentes sejam levados a direcionarem seus investimentos de modo a cometerem erros sistemáticos de avaliação.

\section{III - Teoria Austríaca dos Ciclos DE Negócios}

O ciclo econômico ou ciclo de negócios (business cycle) na visão da Escola Austríaca (EA) é algo mais específico do daquilo que se entende por apenas flutuação econômica. Segundo a escola austríaca, as flutuações econômicas são geradas pela própria incerteza. Algo inerente ao próprio ambiente econômico. As pessoas tentam prever e se antecipar às mudanças do ambiente da forma mais eficiente possível. Os empresários tentam prever os movimentos na demanda e oferta por seus produtos. Os mais bem sucedidos são exatamente aqueles que da melhor maneira são capazes de se antecipar às condições futuras nos seus respectivos ramos de atividade. Entretanto ocorre que a previsão de forma alguma é perfeita, caso contrário não existiriam lucros e perdas nos negócios ${ }^{28}$.

Por outro lado, o ciclo econômico se caracteriza por um largo período de prosperidade econômica (boom) sendo seguido de uma forte contração (depressão) incidente sobre os diversos setores da economia. A teoria austríaca do ciclo de negócios, tal como

\footnotetext{
${ }^{28}$ Inúmeros fatores podem contribuir para o erro de previsão, tais como mudanças nos gostos ou na preferência temporal, choques de oferta, mudanças não esperadas na oferta de trabalho, choques tecnológicos, etc.
} 
originalmente concebida, pode ser descrita da seguinte forma. Segundo Ludwig von Mises $(1881-1973)^{29}$ e F. A. Hayek (1899-1992) ${ }^{30}$, as crises econômicas decorrem do emprego da política monetária na manipulação da taxa de juros, e o consequente aumento no crédito bancário sem ter em contrapartida o crescimento da poupança. Segundo a EA, numa situação onde não exista interferência de qualquer ordem, o aumento do crédito bancário deriva de uma queda da preferência temporal, o que faz com que a relação entre poupança e consumo aumente. Isso tem como consequência a ampliação de recursos para empréstimos no setor bancário, conduzindo a diminuição da taxa de juros. Também a queda na preferência temporal permite ainda a liberalização de fatores de produção. Mais poupança significa menos gastos e mais disponibilidade de recursos para ampliar o crédito bancário. Em relação ao setor real, mais poupança significa menos utilização de fatores produtivos, que agora poderão ser utilizados para novos investimentos, por força da diminuição da taxa de juros, sem pressão sobre o nível de preços.

Um ponto que deve ser ressaltado é que quando a taxa de juros se reduz devido ao aumento da poupança, os empresários ficam propensos a aprofundar a estrutura de capital pela expansão, sobretudo, dos processos intermediários. Isto é, pelo aprofundamento de bens de ordem mais alta (bens de capital) em detrimento de bens de mais baixa ordem (bens de consumo). Para que o crescimento possa ser sustentado, ele deve ser gerado por meio do aumento do crédito bancário saudável, que ocorre devido à queda da preferência temporal. Neste processo, recursos outrora canalizados para o consumo passam a ser conduzidos para criação de novos bens de

${ }^{29}$ MISES, L. von. The Theory of Money and Credit. New Haven: Yale University Press, 1953 [1912]; Idem. Human Action: A Treatise on Economics. Chicago: Henry Regnery, $3^{\text {rd }}$ rev. ed., 1966.

${ }^{30}$ HAYEK, F. A. von. Monetary Theory and the Trade Cycle. New York: Augustus M. Kelley, 1933; Idem. Prices and Production. New York: Augustus M. Kelley, $2^{\text {nd }}$ ed., 1935. capital. Dessa forma, uma nova estrutura de produção mais aprofundada tem origem.

Não obstante, o governo pode igualmente fomentar a expansão do crédito bancário pela expansão dos meios de pagamentos, o que terá o mesmo efeito de redução da taxa de juros. Assim, a expansão do crédito bancário pode também ocorrer pela criação de moeda nova. Neste caso, o aumento da quantidade de moeda eleva a disponibilidade de recursos financeiros para empréstimos. Muito embora, inicialmente, os efeitos sobre a economia sejam similares ao caso anterior, neste caso, por parte do setor real da economia, o aumento do crédito bancário não tem como contrapartida um crescimento no fluxo de fatores de produção disponíveis para serem empregados em novos investimentos. Ao contrário, aqui a queda na taxa de juros por manipulação da autoridade monetária pode reduzir a poupança, tendo em vista a queda do retorno, diminuindo mais ainda o volume de recursos produtivos para fazer face aos novos investimentos por força do aumento do consumo. Assim, é interessante observar que embora existam mais recursos financeiros a disposição do setor bancário - para empréstimos motivados pela expansão dos meios de pagamentos -, na melhor das hipóteses a mesma quantidade de recursos produtivos se encontrará disponível para atender a demanda por novos investimentos, levando fatalmente à pressão sobre os preços.

A criação de moeda nova conduz à queda da taxa de juros devido ao maior fluxo monetário disponível para ser utilizado como crédito. Isso faz parecer que existe um fluxo aumentado de poupança para ser aplicado em novos investimentos. Neste caso, os empresários serão levados a acreditar que a expectativa de lucros dos novos projetos são maiores do que realmente irá ocorrer. A limitação de fatores de produção disponíveis irá gerar, futuramente, aumento no preço dos mesmos, tendo como consequência a diminuição na taxa de lucratividade dos empreendimentos.

Devido também ao aumento da renda do trabalho no setor de bens de capitais, 
e também pelo fato de que a preferência temporal não se altera, em algum momento o preço dos bens de consumo começará gradualmente a crescer, pois não existe disponibilidade imediata de fatores de produção livres para atender ao crescimento da demanda neste setor. Portanto, haverá disputa por fatores que estão, nos estágios da cadeia produtiva, mais próximos ao consumo, levando à aceleração do nível de preços dos setores voltados ao consumo de forma mais rápida que nos outros estágios da produção. Isso faz com que o lucro neste setor se torne relativamente maior que no setor de bens de capital, levando os empresários a repensarem seus investimentos.

Vendo os custos de produção se elevar, devido à disputa por fatores de produção que se estabelece nas indústrias produtoras de bens de consumo, os tomadores de recursos recorrem a novos empréstimos. Os bancos, por sua vez, tendem a prolongar este processo na medida em que socorrem os tomadores de recursos como forma de preservar seus próprios investimentos. Contudo, o processo não pode perdurar indefinidamente. Logo se constatará que houve uma percepção errônea quanto à viabilidade econômica dos novos projetos, levando a revisão dos planos de investimentos. Assim, muitos projetos deverão ser abandonados gerando uma onda de liquidações. Este fenômeno conduz à retração da economia, ou mesmo à chamada depressão.

São necessárias algumas colocações para melhor qualificar o processo de formação do ciclo econômico da Escola Austríaca. Quando o aumento da poupança deriva da queda da preferência temporal, existe uma intensificação no investimento em bens de capital devido a três motivos. Primeiro, devido ao aumento da poupança existirá diminuição dos lucros nos setores que operam na produção de bens de ordem mais baixa. Segundo, temos agora o aparecimento do chamado Efeito Ricardo. O crescimento da poupança leva a uma queda no preço dos bens de consumo, orientando a economia a aprofundar o investimento em bens de capital. Isso leva ao aumento dos salários reais, tornando mais atrativo a inten- sificação de estágios de produção mais capital intensivo, pois o custo do capital diminui em relação ao da força de trabalho. Por fim, é importante observar que a queda na taxa de juros decorrente do aumento da poupança afeta o valor dos bens de capital, sobretudo daqueles que estão nas etapas mais distantes do consumo. $\mathrm{O}$ valor de mercado dos bens de capital tende a ser o valor esperado do fluxo de renda descontado pela taxa de juros. Igualmente, investimentos que antes não eram viáveis se tornam agora economicamente viáveis pela diminuição da taxa de juros.

No caso anômalo em que a expansão do crédito deriva da criação de moeda nova, ocorrerá um efeito Ricardo às avessas. A elevação do preço dos bens de consumo faz com que a remuneração real do fator trabalho diminua em relação à remuneração do capital. Isso faz com que se torne atrativo a substituição de capital por trabalho, diminuindo a demanda por bens de capital, o que agrava ainda mais a queda no lucro das companhias produtoras de bens intermediários e de ordem mais alta.

Um ponto importante a ser ressaltado é a demora na mudança de atitude dos empresários no sentido de diminuir o ritmo do investimento. Para Hayek isso ocorre pois o processo de investimento em bens de capital conduz a uma demanda subsequente por novos bens de capital (complementares). $\mathrm{O}$ processo se aprofundará quanto maior a crença dos investidores de que os projetos devam ser completados.

É comum se propalar a assertiva de que as crises econômicas são geradas por insuficiência no consumo. Contudo, observa-se que durante os períodos de prosperidade, e também de depressão, que a demanda por bens de consumo flutua muito menos que a demanda por bens de capital. De acordo com a EA, o chamado boom deve ser entendido como sendo um estágio de investimento mal induzido e não como alguns costumam nomear de sobre investimento (overinvestment). O período de depressão deve ser entendido como o momento onde a economia 
liquida os investimentos induzidos erroneamente, de modo a reestabelecer uma estrutura de produção adequada à sua preferência temporal. Portanto, antes de ser entendida como um mal, a depressão é antes de tudo o modo benéfico e eficiente pelo qual a economia retorna a seu ritmo normal, após as distorções geradas pelo governo no período de prosperidade econômica. Quanto maior e mais prolongada for a expansão do crédito mais longo e forte se dará a expansão da economia. Contudo, maior também será a depressão, de modo que a economia restaure a estrutura de capital adequada a sua preferência temporal.

A teoria exposta acima assume por hipótese que o instrumento de política monetária se concentra fundamentalmente no controle da moeda. Contudo, a ênfase quanto ao instrumento a ser utilizado pela autoridade monetária tem mudado nos tempos mais recentes para o controle da taxa de juros ${ }^{31}$. Por exemplo, esta política começou a ser adotada nos EUA a partir do final da década de 1980, enquanto no Brasil isso se consolidou a partir de 1999, quando foi introduzido o regime de meta de inflação. O controle da taxa de juros propicia de modo mais frequente o uso da chamada sintonia fina, que consiste em promover uma política discricionária de ajustamento da taxa de juros visando atingir uma meta estabelecida de política econômica. Tomando o caso dos Estados Unidos, a aplicação da política de sintonia fina no controle da taxa de juros tem gerado na nossa visão forte instabilidade do produto e ampliação do ciclo econômico. Sendo o mesmo válido para o Brasil.

\section{IV - AbORdAgEM EMPÍRICA}

Tratemos agora de ver como a Teoria Austríaca do Ciclo Econômico (TACE) pode nos auxiliar na questão sobre a existência de bolha especulativa no mercado imobiliário. Muito embora a TACE tenha sido elaborada para elucidar as crises econômicas de caráter mais

\footnotetext{
${ }^{31}$ Comoésabido, nãose pode controlar simultaneamente a taxa de juros e a oferta de moeda.
}

geral, alguns elementos dessa teoria podem ser usados para analisar essa questão. Vejamos então como podemos melhor qualificar a TACE, para propiciar hipóteses testáveis empiricamente que ajudem a elucidar a questão da bolha especulativa no mercado de imóveis no Brasil.

De acordo com a teoria austríaca, o ciclo econômico se caracteriza por um largo período de expansão na economia seguido de uma forte contração. Ambos incidentes sobre os diversos setores da economia. No entanto, é possível observar situações onde a expansão econômica, provocada de modo artificial, pode se concentrar inicialmente em determinados setores. Foi isso o que ocorreu na crise do mercado imobiliário americano. A conjugação de três fatores contribuiu para que houvesse um boom nesse segmento da economia. Primeiro, a manutenção da taxa de juros num patamar muito baixo por um longo período. Segundo, políticas públicas orientadas no sentido de universalizar a aquisição do imóvel próprio para o segmento de baixa renda, promovidas pelas agências, forçaram o sistema bancário a baixar sobremaneira os requisitos para obtenção de crédito $^{32}$. Por fim, as restrições de diversas categorias impostas sobre a construção de imóveis em determinadas áreas dos Estados Unidos restringiu a oferta, elevando o preço acentuadamente em determinadas áreas (Leesburg, San Jose, Palo Alto e Manhattan, etc) enquanto que em outras localidades o crescimento do preço da moradia foi bem mais modesto, como em Houston e Dalas, por exemplo ${ }^{33}$.

A TACE aponta que as crises econômicas decorrem do emprego da política monetária na manipulação da taxa de juros, e o consequente aumento no crédito bancário, sem ter em contrapartida o crescimento da poupança. Sabemos que a taxa de juros incidente sobre o financia-

${ }^{32}$ LEIBWITZ, S. J. Anatomy of a Train Wreck: Causes of the Mortgage Meltdown. Independent Policy Report. The Independent Institute, 2008.

33 SOWELL, T. Applied Economics. New York: Basic Books, 2nd ed., 2008. Idem. The Housing Boom and Bust. New York: Basic Books, 2009. 
mento imobiliário, embora seja ainda muito alta em relação àquela praticada nos países desenvolvidos, é subsidiada, variando aproximadamente entre $8 \%$ a $12 \%$ ao ano. Tal taxa depende tanto de características sócio-econômicas do tomador de empréstimo como também de características do imóvel. Apesar de alta para padrões de países desenvolvidos, tal taxa se situa num nível muito abaixo ao que é cobrado em outras operações bancárias convencionais. Isso porque aproximadamente $70 \%$ dos recursos para o crédito imobiliário são fornecidos pela caderneta de poupança, que paga ao depositante uma taxa ainda menor, em torno de $6 \%$ ao ano, taxa essa que irá se reduzir em decorrência das novas regras aprovadas pelo governo para a remuneração da caderneta de poupança ${ }^{34}$.

Também no Brasil existe uma política pública instituída de fomento da indústria da construção civil, tanto em obras no setor de infraestrutura como em segmentos do setor imobiliário. Os megaeventos da Copa do Mundo em 2014 e as Olimpíadas do Rio de Janeiro em 2016 fizeram o governo levar a cabo um grande números de obras públicas, que estão trazendo alterações importantes onde tais obras estão sendo acontecendo. Isso tem gerado uma perspectiva de valorização dos imóveis cuja localização sofra influência de alguma delas. Conjuntamente, o emprego do crédito subsidiado para a compra de imóvel residencial tem ajudado substancialmente a aquecer o mercado imobiliário. Além disso, de modo semelhante ao que aconteceu nos EUA, o governo tem promovido políticas visando aquisição da casa própria para certos segmentos de baixa renda, tal como o programa Minha Casa Minha Vida. Assim, é natural que a conjunção desses importantes fatores de direcionamento de investimentos tenha criado um ambiente que faz com que a demanda esteja fortemente aquecida no setor imobiliário.

Tendo em vista o que foi dito acima, seguiremos agora cinco diferentes abordagens

\footnotetext{
${ }^{34}$ As novas regras de remuneração da caderneta de
} poupança passaram a vigorar em maio de 2012. empíricas, engendradas com base nos fundamentos da Teoria Austríaca do Ciclo Econômico, para verificar a existência de bolha no mercado imobiliário. Inicialmente, na seção IV.1 verificaremos se o preço corrente dos imóveis responde aos fundamentos com base na equação (1). De acordo com os preceitos da Escola Austríaca, o efeito acusado pelo contínuo aumento da atividade na construção civil irá cedo ou tarde repercutir no custo na construção. Assim, na seção IV.2, levamos a cabo um exercício econométrico como objetivo verificar se existe pressão sobre a estrutura de custo de construção advinda da demanda por imóveis no setor.

Os dois testes seguintes se concentram na perspectiva macroeconômica. $\mathrm{O}$ primeiro deles visa checar o estado da política fiscal no Brasil enquanto o segundo tem por objetivo medir o efeito de um aumento inesperado da taxa de juros sobre variáveis fundamentais, tais como o produto industrial da construção civil e o crédito imobiliário. Conhecer o estado da política fiscal é útil por permitir verificar em que medida a política fiscal tem exercido pressão sobre a taxa de inflação. No caso de existir uma forte pressão sobre a taxa de inflação decorrente de uma política fiscal expansiva, a taxa de juros terá que em algum momento se ajustar, e o efeito deste ajuste pode ter impacto importante sobre variáveis fundamentais ligadas ao setor imobiliário. Assim, o teste subsequente implementado com base na metodologia VAR estrutural, tem exatamente o propósito de checar o efeito de um choque de política monetária, representado pelo aumento da taxa de juros, sobre variáveis como o produto industrial da construção civil e o fluxo de crédito imobiliário.

\section{IV.1 - Estimação da Equação Fundamental}

Nesta seção apresentaremos os resultados da estimação da equação fundamental para o preço dos imóveis, utilizando dados de séries de tempo agrupados para os estados de São Paulo e Rio de Janeiro. Embora a informação acerca do preço de venda do imóvel 
esteja disponível para outras capitais, o mesmo não ocorre para o preço do aluguel. Nas estimativas de séries temporais estimaremos uma vertente da seguinte regressão

$$
q_{t}=\beta_{0}+\beta_{1} E_{1} q_{t+1}+\beta_{2} d_{t}+\beta_{3} i_{t}+\beta_{4} S P+v_{t+1} .
$$

Onde: $q_{t}$ é o preço de venda do imóvel, $d_{t}$ é o preço do aluguel, $i_{t}$ a taxa de juros, e $S P$ uma variável dummy para diferenciar a região de São Paulo. Como proxy para $E_{1} q_{t+1}$, usaremos o próprio valor da variável $q_{t}$ em $t+1$, procedimento que embute um erro de medida, e para a taxa de juros, a taxa Selic. Os sinais esperados para os parâmetros associados às variáveis $E_{1} q_{t+1}$ e $d_{t}$ possuam sinal positivo enquanto que para a variável $i_{t^{\prime}}$ o sinal esperado é negativo.

Usaremos aqui três procedimentos econométricos distintos para estimar a equação (7): método de mínimos quadrados ordinários (MQO), método de variáveis instrumentais (IV) e pelo método de momentos generalizados (GMM). O emprego do método de variáveis instrumentais para estimar (1) decorre do operador de expectativas racionais na equação que não é observado. Tomando $q_{t+1}=E\left[q_{t+1} \mid I_{t}\right]+v_{t+1}$, onde $E\left[v_{t+1} \mid I_{t}\right]=0$, temos que usando $q_{t+1}$ ao invés de $E\left[q_{t+1} \mid I_{t}\right]$, estaremos sujeito a crítica relativa ao erro de medida caso a estimação seja feita por MQO.

Antes de comentarmos os resultados, façamos uma digressão acerca dos testes econométricos adotados aqui para verificar se a regressão está bem especificada. Embora muitos estudos utilizem a abordagem GMM para estimação de modelos com expectativas racionais, deve-se assinar que esta metodologia não necessariamente é superior à estimação por variáveis instrumentais. Tal como ressalta Christopher F. Baum, Mark E. Schaffer e Steven Stillman, a vantagem da abordagem GMM se dá na presença de heteroscedasticidade $^{35}$. Neste caso, a vantagem da consistência

\footnotetext{
${ }^{35} \mathrm{O}$ estimador IV embora seja consistente, é ineficiente na presença de heterocedasticidade. Ver: BAUM, C. F. ; SCHAEFFER, M. E. \& STILLMAN, S. Enhanced
}

do estimador GMM na presença de heteroscedasticidade é contrabalançada pelo custo de uma performance fraca no caso de pequenas amostras. Deste modo, quando o problema da heteroscedasticidade não se faz presente, é preferível ainda o emprego do estimador de variáveis instrumentais. Usamos neste estudo o teste de Pagan e Hall ${ }^{36}$ para checar a ocorrência de heteroscedasticidade no modelo ${ }^{37}$.

Para que a aplicação do método IV seja adequada, é necessário que os instrumentos sejam "bons instrumentos" no sentido de serem relevantes bem como válidos. No jargão econométrico isso significa que as variáveis usadas como instrumentos devam ser correlacionadas com os regressores endógenos e ao mesmo tempo ortogonais ao distúrbio da regressão. Neste sentido são mostrados na mesma Tabela o teste de sub-identificação de Cragg-Donald ${ }^{38}$, o teste de sobre-identificação de Hansen-Sargan ${ }^{39}$, o teste de endogeineidade

Routines for Instrumental Variables/GMM Estimation and Testing. Boston College Economics Working Paper, No. 667 (2007).

${ }^{36}$ PAGAN, A. R. \& HALL, D. Diagnostic Tests as Residual Analysis. Econometric Reviews, Vol. 2, No. 2 (1983): 159-218.

37 Este teste assume a hipótese nula de homocedasticidade.

${ }^{38}$ Para que uma equação seja identificada no modelo IV tanto a condição de ordem ( $\mathrm{L}>=\mathrm{K})$, onde $\mathrm{L}$ é o número de variáveis instrumentais e Ko número de regressores, como a condição do posto devem ser preenchidas. Esta última assinala que $\mathrm{Qxz}=\mathrm{E}\left(\mathrm{X}^{\prime} Z\right)$ deve ser de posto completo, onde $X$ é a matriz de regressores, enquanto $Z$ é a matriz dos instrumentos. Quando isso não ocorre dizemos que o modelo é sub-identificado ou não identificado. No teste de Cragg-Donald, a rejeição da hipótese nula sugere que o modelo é identificado. Ver: CRAGG, J. G. \& DONALD, S. G. Testing Identifiability and Specification in Instrumental Variables Models. Econometric Theory, 9 (1993): 222-240.

${ }^{39}$ A independência do instrumento com relação ao distúrbio somente pode ser acessada se, e somente se, houver uma "abundância" de instrumentos, isto é, se a equação é sobre-identificada. Isto se dá quando a condição de ordem é satisfeita na desigualdade: o número de instrumentos excluídos é superior ao regressores endógenos. O teste de Hansen-Sargan é usado para testar a hipótese de sobre-identificação. 
dos regressores de Durbin-Wu-Hausman ${ }^{40}$ $(\mathrm{DWH})$, além do teste de Stock-Yogo ${ }^{41}$ para verificar se os instrumentos são fracos ${ }^{42}$.

A pesquisa teórica econométrica mais recente sobre o método de variáveis intrumentais tem enfatizado muito a questão dos instrumentos fracos ${ }^{43}$. Adrian Ma aponta que o uso de instrumentos pode ser um sério problema em modelos econométricos ${ }^{44}$. Quando os instrumentos são fracos, dois problemas sérios ocorrem na estimação por dois estágios (2SLS). O primeiro é a questão do viés. Embora o método 2SLS seja consis-

Sob a hipótese nula os instrumentos são válidos, ou seja, não correlacionados com o distúrbio. Sob ainda esta hipótese, a estatística de teste tem distribuição quiquadrado com L-K restrições sobre-identificadas. Ver: HANSEN, L. Large Sample Properties of Generalized Method of Moments Estimators. Econometrica, Vol. 50, No. 3 (1982): 1029-54.

${ }^{40}$ Sob a hipótese nula este teste especifica que o regressor tomado como endógeno pode ser tratado como exógeno. A estatística DWH possui distribuição qui-quadrado com grau de liberdade igual ao número de regressores endógenos. Ver: WU, D. Alternative Tests of Independence Between Stochastic Regressors and Disturbance. Econometrica, 41 (1973): 733-50.

${ }^{41}$ STOCK, J. H. \& YOGO, M. Testing for Weak Instruments in Linear IV Regression. In: ANDREWS D. W. \& STOCK, J. H. (Ed.). Identification and Inference for Econometric Models: Essays in Honor of Thomas Rothenberg. Cambridge: Cambridge University Press, 2005. p. 80-108.

42 Instrumentos que explicam pouco a variação da variável explicativa endógena (fraca correlação entre $\mathrm{Z}$ e $\mathrm{X}$ ) são considerados instrumentos fracos. O teste de Stock-Yogo é calculado com base na estatística F do teste de Cragg-Donald. Sob a hipótese nula o estimador é fracamente identificado no sentido de que o viés verificado é inaceitavelmente grande.

${ }^{43}$ STOCK, J. H.; WRIGHT, J. H. \& YOGO, M. A Survey of Weak Instruments and Weak Identification in Generalized Method of Moments. Journal of Business and Economic Statistics, Vol. 20, No. 4 (2002): 51829; MOREIRA, M. J. A Conditional Likelihood Test for Structural Models. Econometrica, Vol. 71, No. 4 (2003): 1027-48; STOCK \& YOGO. Testing for Weak Instruments in Linear IV Regression.

${ }^{44}$ MA, A. GMM Estimation and the New Phillips Curve. Economic Letters, 76 (2002): 411-17. tente $^{45}$, as estimativas são sempre viesadas para pequenas amostras. Segundo, quando os instrumentos são fracos, o erro padrão estimado se torna muito pequeno. Neste caso, o intervalo de confiança é não fidedigno, pois juntamente ao fato de que o ponto médio deste estimador ser viesado, temos então que o intervalo de confiança se torna pequeno. Isso tudo faz com que o procedimento de teste de hipótese na estimação por 2SLS se fragilize no caso da ocorrência de instrumentos fracos.

Vários testes são sugeridos na literatura para testar a hipótese de instrumentos fracos ${ }^{46,47}$. De acordo com Michael P. Murray a mais recente abordagem em relação ao problema de teste de hipótese com instrumentos fracos e um único regressor endógeno é o "teste da razão de verossimilhança condicional"48, desenvolvido por Marcelo J. Moreira ${ }^{49}$ e aperfeiçoado em Donald W. K. Andrews, Marcelo J. Moreira e James H. Stock ${ }^{50}$. O teste de Moreira supera as distorções encontradas nos testes convencionais ajustando os valores críticos do teste de hipótese de acordo com cada amostra, de modo que o intervalo de confiança corrigido gere um nível de significância correto. Assim,

${ }^{45}$ De modo que quase certamente o valor médio do estimador 2SLS se aproxima do verdadeiro valor do parâmetro quando o tamanho da amostra convirja para o infinito.

${ }^{46}$ James H. Stock e Motohiro Yogo sugerem um teste onde a hipótese nula é que o viés do estimador 2SLS seja menor que uma fração (digamos, 10\%) do estimador OLS. Ver: STOCK \& YOGO. Testing for Weak Instruments in Linear IV Regression.

${ }^{47} \mathrm{O}$ teste de Stock-Yogo não mais recai na estatística $F$ que comumente aparece na prática econométrica, mas numa generalização da estatística do teste de CraggDonald. Os valores críticos deste teste são obtidos a partir de uma distribuição não padrão.

${ }^{48}$ MURRAY, M. P. Avoiding Invalid Instruments and Coping with Weak Instruments. Journal of Economic Perspectives, Vol. 20, No. 4 (2006): 111-32.

49 MOREIRA. A Conditional Likelihood Test for Structural Models.

${ }^{50}$ ANDREWS, D. W. K. ; MOREIRA, M. J. \& STOCK, J. H.. Optimal Two-sided Invariant Similar Tests for Instrumental Variables Regression. Econometrica, Vol. 74, No. 3 (2006): 715-52. 
seus valores críticos "são condicionados" nos dados à disposição e não constante ${ }^{51}$.

Passemos agora à análise dos resultados econométricos obtidos para a equação (7) apresentados na Tabela 3. Estranhamente, na regressão estimada da coluna (1), apenas com exceção do preço futuro do imóvel, os sinais para a taxa Selic e o preço do aluguel são contrários ao esperado. Na coluna (2), estima-se por MQO uma equação onde somente o preço de venda futuro está fora do conjunto de regressores. Pode-se observar que agora ambas variáveis taxa Selic e o aluguel apresentam os sinais esperados. Embora não seja mostrado aqui por economia, estimamos uma regressão contendo apenas a taxa Selic como variável importante e observamos que o sinal negativo se manteve. Enquanto outro exercício usando apenas o preço do aluguel na regressão mostrou também que o sinal positivo para essa variável se preserva.

Algumas possíveis respostas podem ser dadas para explicar por que a regressão da coluna (1) não apresenta os sinais esperados enquanto temos os sinais apropriados para aquela da coluna (2). Primeiro, o termo $E_{1} q_{t+1}$ representa na equação (7) a expectativa de valorização do imóvel. Contudo, espera-se naturalmente que isso ocorra num período de tempo adiante, mas não imediatamente à frente, tal como no mês seguinte. No caso de um imóvel comprado na planta, estipula-se que o prazo mínimo razoável para sua revenda é de um ano e meio a dois anos, pelo menos. Assim, quando usamos dados com frequência temporal mensal, a formação de expectativa um mês à frente não capta o efeito da valorização futura no preço corrente do imóvel. Neste caso, o uso de dados anuais seria bem mais apropriado com vista a captar tal efeito ${ }^{52}$. Segundo, tendo em vista a rigidez por força dos contratos no caso do preço do aluguel, uma alteração nessa variável ocorre somente com certa defasagem. Por esse

51 MOREIRA. A Conditional Likelihood Test for Structural Models.

${ }^{52}$ Infelizmente o tamanho da nossa amostra para dados anuais é de apenas quatro anos. motivo, o valor corrente do preço do aluguel tem significância no preço corrente do imóvel. Terceiro, é admitir a hipótese de que o preço futuro de venda é altamente correlacionado como o preço corrente do aluguel ou a taxa Selic. Vejamos se essa hipótese é convincente.

Na segunda coluna da tabela 3, estima-se a mesma regressão por MQO. Nosso objetivo aqui verificar se existe a existência de multicolinearidade no modelo por meio da estatística VIF53. De fato, o valor 18.39 para esta estatística excede em muito o devido, pois a literatura assinala que existe indicação de multicolinearidade se o VIF for maior que $5^{54}$. Na coluna (3), refazemos a estimação por MQO se incluir o preço futuro de venda. Note que agora tanto o preço do aluguel como a taxa de juros se mostram significativos e com os sinais esperados. Também neste caso, a estatística VIF indica que não existe problema de multicolinearidade na regressão. Na coluna (4) apresentamos uma maneira indireta de tentar captar o efeito da expectativa do preço futuro de venda na equação fundamental. Isso foi feito introduzindo no conjunto dos regressores ao invés do preço futuro, o resíduo da regressão (RES) dessa variável contra a taxa de juros e o preço do aluguel. $\mathrm{O}$ resultado disso, mostrado na coluna (4), parece indicar que a expectativa de valorização tem efeito sobre o preço corrente do imóvel. A variável Res é significativa e mostra ainda o sinal esperado.

O exercício efetuado nas duas últimas colunas da tabela 1 consiste fundamentalmente em empregar a expectativa em relação ao preço futuro do aluguel ao invés do seu valor corrente. Na coluna (5) deixamos de fora a expectativa de preço futuro de venda enquanto na coluna (6) o método descrito acima é usado para detectar o efeito dessa variável. Tendo em a presença de heteroscedastidade no modelo indicada pelo teste de Pagan-Hall, a estimação

\footnotetext{
${ }^{53}$ Variance Inflation Factor.

${ }^{54}$ JUDGE, G. ; HILL, C. ; GRIFFITHS, W. ; LEE, T. \& LÜTKEPOL, H. Introduction to the Theory and Practice of Econometrics. New York: Wiley, 1982.
} 
Tabela 1: Variável dependente: Preço do Imóvel*

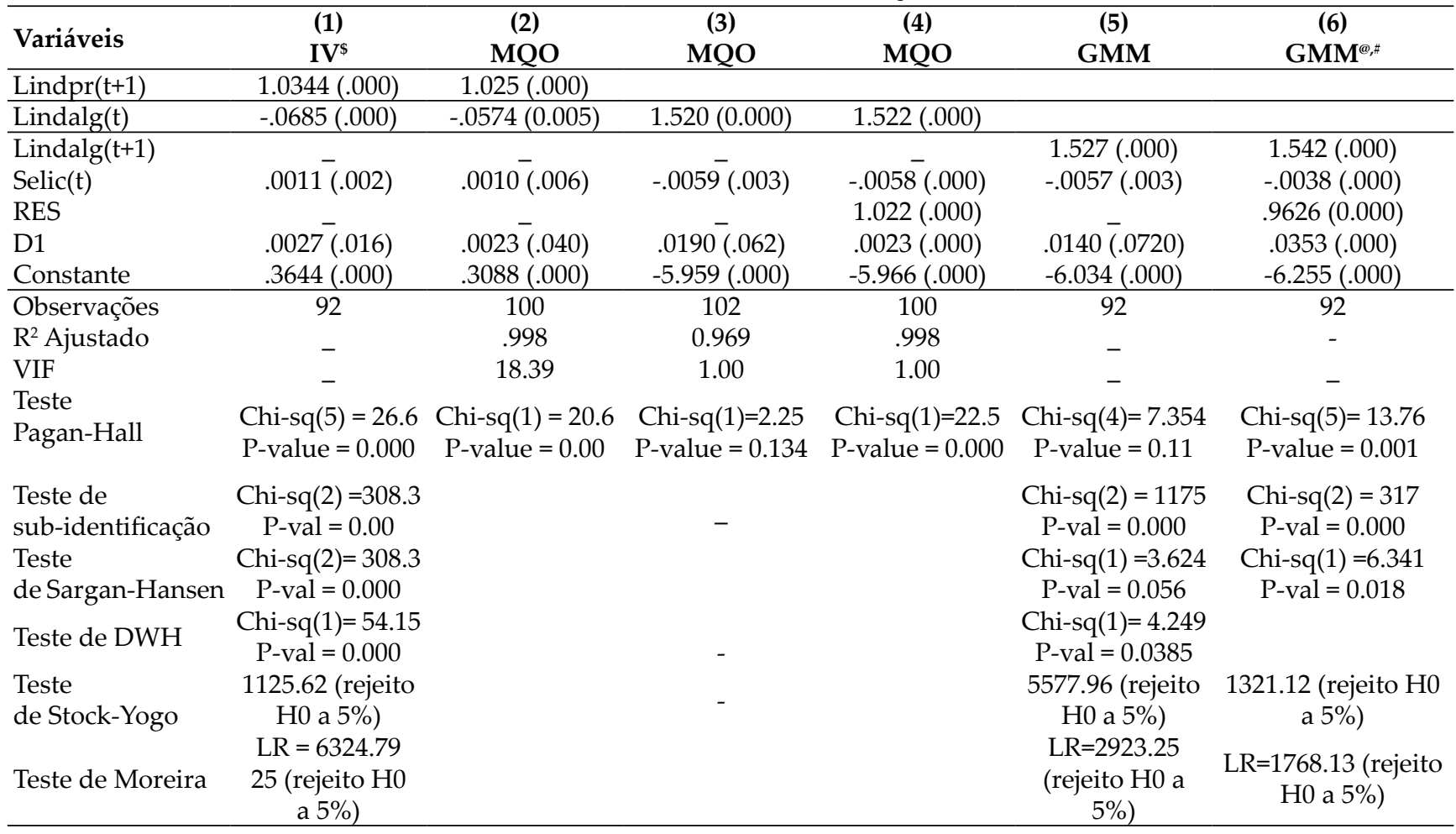

*Lindpr: ln do índice de preço de venda do imóvel. Lindalg: ln do índice de preço do aluguel. ${ }^{\circledR}$ As estatísticas são robustas para resíduos heterocedásticos. Os valores entre parênteses são valores-p. ${ }^{\$}$ A expectativa foi instrumentalizada pelas defasagens de segunda e terceira ordem da variável preço de venda. ${ }^{*}$ A expectativa foi instrumentalizada pelas defasagens de segunda e terceira ordem da variável preço do aluguel.

foi feita usando o método GMM. Também a estimativa foi refeita usando pelos métodos IV robusto ${ }^{55}$, mas os resultados não apresentaram mudança significativa.

Por fim, o teste DWH indica que nos casos analisados das colunas (1), (5) e (6); expectativa do preço futuro de venda ou do aluguel não pode ser tratada como varável exógena no modelo. No que se refere ao problema de instrumentos fracos, os testes de Moreira e de Sock-Yogo não indicam qualquer sinal de que as variáveis instrumentais empregadas sejam instrumentos são fracos. Também de acordo com o teste de Cragg-Donald, em todos os casos os modelos estão identificados onde se aplica o método IV. Igualmente, nesses mesmos casos, temos para todos os modelos não se rejeita a hipótese de sobre-identificação.

${ }^{55}$ Especifica a aplicação do estimador Eicker/Huber/ White para a variância do estimador IV.

\section{IV.2 - Existe pressão inflacionária na construção civil?}

Conforme visto na primeira seção, determinados pesquisadores argumentam que a bolha imobiliária brasileira se comprovaria pelo fato de que o preço dos imóveis estaria acima daquilo que se supõe como sendo o preço justo. Tal preço, segundo esse raciocínio, deve cobrir os custos de produção, bem como conter uma margem para cobertura das incertezas. De acordo com os fundamentos da Escola Austríaca (EA), o erro dessa argumentação está no fato de que o valor de um bem decorre da utilidade que os indivíduos dão a ele. O preço de mercado é determinado pela importância que as pessoas têm por ele. Decorre desse raciocínio, que a estrutura de custo de um produto está indiretamente relacionada por quanto os indivíduos aceitam pagar pelo produto. Fatores de produção usados na confecção de um bem altamente 
valorado tendem a se tornar mais caros e, vice-versa. Assim, segundo a EA a causalidade é mais em direção do preço para o custo que o contrário, isto é, a valoração de um bem é o que determina seu custo e, não o contrário.

Uma maneira de verificar se a hipótese de que a causalidade é no sentido do preço do imóvel em direção ao seu custo e não o contrário pode ser feita, checando a hipótese de exogeneidade do preço do imóvel $\left(q_{t}\right)$ na equação que descreve o custo de construção $\left(c_{t}\right)$. Essa equação pode ser posta da seguinte maneira:

$$
c_{t}=\alpha_{0}+\alpha_{1} q_{t}+\alpha_{2} i_{t}+\alpha_{3} S P+u_{t} .(8)
$$

Onde: $c_{t}$ é o custo de contrução, $i_{t}$ a taxa de juros, $q_{t}$ é o preço de venda do imóvel e $S P$ uma variável dummy para diferenciar a região. Como proxy para o custo de construção, usamos aqui o índice do custo da construção calculado pelo IBGE e para a taxa de juros, a taxa Selic. Espera-se que sinal esperado para o parâmetro associado à variável $q_{t}$ seja positivo enquanto que para a variável $i_{t}$, o sinal esperado para o parâmetro é negativo. A informação de preço de venda $q_{t}$, usado aqui é o índice de preço do imóvel anunciado ${ }^{56}$ quando variável certa deveria ser preço de venda do imóvel novo. Assim, a hipótese admitida aqui para contornar essa restrição é que ambas as medidas seguem a mesma tendência de crescimento ao longo do tempo, o que parecer ser uma suposição razoável.

Em modelos com somente uma equação, caso as variáveis do lado direito não sejam exógenas, a regressão não será eficiente e pode ser melhorada por um sistema de equações. Então em um modelo de uma equação, é necessário verificar se que as variáveis explicativas são exógenas. Usaremos três procedimentos para testar a questão da exogeneidade da variável $q_{t}$ na equação (8), que denotaremos por equação condicional (EC). Pelo fato de existir mais de uma maneira de definir exogeneidade, estaremos aqui trabalhando

56 FIPE. Índice FIPEZAP de Preços de Imóveis Anunciados: Notas Metodológicas (2011). com o conceito de exogeneidade fraca. Os dois primeiros testes de exogeneidade fraca requerem construir uma equação marginal para a variável no lado direito da equação que se supõe possa não ser exógena. Deve-se admitir que não existe uma maneira geral de construir a equação marginal (EM). Usaremos duas equações marginais para tratar $\mathrm{o}$ processo gerador de $q_{t}$ tal como descrito na Tabela 2 a seguir.

TABela 2 - EquaÇões marginais Para o PREÇo DO IMÓVEL

\begin{tabular}{|c|c|}
\hline EM_1 & EM_2 \\
$q_{t}=\alpha_{0}+\alpha_{1} d_{t}+\alpha_{2} i_{t}+\alpha_{3} S P+\varepsilon_{t}$ & $q_{t}=\alpha_{0}+\sum_{t}^{3} \alpha_{t} d_{t-t}+\alpha_{2} i_{t}+\alpha_{3} S P+\varepsilon_{t}$ \\
\hline
\end{tabular}

$d_{t}$ é o preço de venda do imóvel

A literatura aponta diversas maneiras de se testar exogeneidade fraca ${ }^{57}$. Neste estudo faremos três diferentes para verificar se o preço do imóvel atende esta propriedade na equação do custo (8). O primeiro teste foi proposto em 1982 por Robert F. Engle e consiste verificar a correlação entre os erros das equações marginais (1 e 2) com os erros da equação condicional $(8)^{5}$. Uma baixa correlação seria um sinal em favor da aceitação da hipótese de fraca exogeneidade e, portanto a estimação com base em uma única equação é eficiente. A tabela 3 mostra o resultado. Conforme pode ser visto, observa-se uma baixa correlação entre os erros das equações condicional e as marginais.

TABela 3 - Correlação entre o erro das EQUAÇÕES MARGINAL E CONDICIONAL

\begin{tabular}{ll|ll} 
EM_1 & -0.0107 & EM_2 & -0.0125
\end{tabular}

\footnotetext{
${ }^{57}$ AdolfoSachsida faz uma ampla revisão sobre o tema de exogeneidade. Ilustrando inclusive os procedimentos necessários para se operacionalizarem os testes. Ver: SACHSIDA, A. Testes de Superexogeneidade na Correlação Poupança-Investimento. Texto para Discussão do IPEA, No. 659. Brasília, julho de 1999. Disponível em: http://www.dominiopublico.gov.br/ download/texto/td_0659.pdf

${ }^{58}$ ENGLE, R. F. A General Approach to Lagrange Multiplier Model Diagnostics. Journal of Econometrics, Vol. 20, No. 1 (1982): 83-104.
} 
O segundo teste usado para verificar exogeneidade fraca é uma modificação, feita em 1984, do teste de Engle ${ }^{59}$. Aqui, o erro da equação condicional é incluído nas equações marginais. Se o erro da equação condicional não é estatisticamente significativo no processo marginal, isto significa o preço do imóvel é fracamente exógeno na equação condicional. A tabela 4 mostra os resultados deste teste. Verifica-se que o erro da equação condicional não apresenta significância estatística em ambos os processos marginais. Então, com base no teste modificado de Engle (1984), conclui-se que o preço do imóvel é fracamente exógeno na equação condicional (8).

O terceiro procedimento para verificar endogeneidade se faz usando o teste Durbin-Wu-Hausman (DWH) que tem como base a estimação da equação condicional pelo método de variáveis instrumentais (VI) com o objetivo de checar a existência de endogeneidade nessa equação ${ }^{60}$. A hipótese nula do teste assinala que a estimação por MQO da equação renderia a estimativas consistentes. A rejeição da hipótese nula indica que o regressor é endógeno e, por consequência, a estimação por IV é exigida. Este teste foi aplicado tomando o

preço $q_{t}$ com endógena e usando os conjuntos de instrumentos definidos pelas equações marginais 1 e 2 . Em ambos os casos, o teste de DWH não rejeitou a hipótese nula de exogeneidade para essa variável. Assim, tendo em vista os três testes dessa seção, concluímos que a estimação da relação entre o custo e preço do imóvel por somente uma equação é eficiente.

Tabela 4: Teste modificado de Engle (1984)

Significância estatística do $\quad$ Significância estatística do erro da EC na EM_1: $\quad$ erro da EC na EM_2: P-valor: 0.991 P-valor: 0.5971

59 Idem. Wald, Likelihood Ratio and Lagrange Multiplier Tests I Econometrics. In: GRILICHES, Z. \& INTRILIGATOR, M. D. (Ed.). Handbook of Econometrics. Amsterdan: North-Holland Publishing Co., 1984. V. 2.

${ }^{60}$ WU. Alternative Tests of Independence Between Stochastic Regressors and Disturbance.
No conjunto, esses testes sugerem que é o preço do imóvel que exerce pressão sobre o custo, e não o inverso. O que se constitui num argumento favorável à percepção da Escola Austríaca.

\section{IV.3 - Avaliando a condição fiscal no Brasil}

O objetivo dessa seção é avaliar o estado da política fiscal no Brasil. Uma medida quantitativa do estado da política fiscal é útil por pelo menos duas razões. Primeiro, saber quão restritiva, ou expansiva, é a condição fiscal no momento corrente ajuda o policy maker a determinar o curso da política fiscal necessário a manter a dívida pública dentro de uma meta estabelecida para um dado horizonte de tempo, o que contribui para o controle da inflação. Em segundo lugar, uma medida quantitativa da posição fiscal é importante por razões históricas, indicando os períodos precisos em que a política fiscal foi mais acomodativa ou mais restritiva.

Infelizmente, não há nenhum método universalmente aceito para mensurar o estado da política fiscal. Diferentes autores sugerem maneiras distintas de tratar esta questão ${ }^{61}$. $\mathrm{O}$ principal problema em considerar os indicadores já existentes como métodos fidedignos para avaliação da condição fiscal diz respeito à dificuldade em distinguir uma mudança discricionária (por exemplo, uma decisão unilateral do Tesouro para aumentar a carga fiscal da economia) daquela oriunda do componente não discricionário da política fiscal, mudanças essas endógenas ao estado de economia. Aqui podemos citar como exemplo o crescimento da carga tributária devido à

${ }^{61}$ BLANCHARD, O. J. Suggestions For a New Set of Fiscal Indicators. OECD Economics and Statistics Department, 1993 (Working Paper, n. 79); DE LEEUW, F. \& HOLLOWAY, T. M. The Measurement and Significance of the Cyclically Adjusted Federal Budget and Debt. Journal of Money, Credit and Banking, Vol. 17, No. 2 (1985): 232-42; ALESINA, A. \& PEROTTI, R. Fiscal Adjustments in OECD Countries: Composition and Macroeconomic Effects. Washington: International Monetary Fund (IMF), 1997. (Working Paper, No. 96/70). 
diminuição do grau de informalidade assim como o aumento da despesa pública em consequência dos gastos com seguro-desemprego em momentos de recessão.

Nesta pesquisa nós usamos o modelo de previsão condicional para avaliar a condição da política fiscal no Brasil com dados do governo central para o período de janeiro de 1997 até março de 2012. Como observado anteriormente, nosso indicador é medido pela diferença dos valores preditos para o hiato do produto quando condicionado aos valores observados e de equilíbrio estacionário dos instrumentos de política fiscal - carga tributária líquida e gastos correntes do governo. Este índice é uma tentativa de responder qual o efeito de uma mudança nos instrumentos de política fiscal sobre variáveis representativas dos objetivos de política econômica, tal como o produto ou a taxa de inflação. Tendo em vista um modelo econômico em que todas as variáveis envolvidas são endógenas, a informação que procuramos é quanto uma mudança no hiato do produto (ou na inflação) em relação ao nível de tendência se deveu a uma alteração discricionária na política fiscal.

O emprego do método de projeção condicional para acessar o estado de política foi proposto originalmente por Brisne J. V. Céspedes, Elcyon C. R. Lima, Alexis Maka e Mário J. C. Mendonça com o objetivo de avaliar a condição da política monetária para a economia brasileira ${ }^{62}$. Mário J. C. Mendonça, Luis Alberto T. Medrano e Adolfo Sachsida aplicam o mesmo método para acessar o estado da política fiscal com dados do governo geral $^{63}$. A validez deste método foi reconhecida

${ }^{62}$ CÉSPEDES, B. ; LIMA, E. ; MAKA, A. \& MENDONÇA, M. J. Measuring Monetary Policy Stance in Brazil. Texto para Discussão do IPEA, No. 1128. Rio de Janeiro, Outubro de 2005. Disponível em: http:// www.ipea.gov.br/portal/index.php?option $=\mathrm{com}_{-}$ content\&view $=$ article\&id=4309

${ }^{63}$ Os dados são trimestrais para o período de janeiro de 1995 a dezembro de 2007. O governo geral composto pelo Governo Central (o governo federal, agências federais etc.) e governos regionais (estados e municípios). Ver: MENDONÇA, M. J. ; MEDRANO, na literatura. Merek Jarocinski e Frank Smets usam este indicador para encontrar as implicações do preço dos imóveis para a condição da política monetária nos Estados Unidos ${ }^{64}$.

$\mathrm{Na}$ literatura econômica a discussão sobre o estado da política fiscal aparece relacionada à identificação do componente discricionário de política, isto é, aquelas mudanças que resultam das ações intencionais levadas a cabo pelo policy maker. Desnecessário mencionar que alterações dos gastos e receitas do governo que derivam do efeito do ciclo econômico não podem ser caracterizadas como sendo induzidas pela política fiscal. Uma definição mais sofisticada baseia-se no conceito do déficit de pleno emprego, o déficit primário observado quando a economia está no pleno emprego. A diferença é que o déficit de pleno emprego observado determinaria o componente cíclico das contas públicas. O problema neste caso consiste na estimação do déficit de pleno emprego, tarefa nada trivial.

Olivier Jean Blanchard sugere uma maneira muito atrativa de tratar este problema sem prejuízo da simplicidade ${ }^{65}$. Sua medida ainda toma o ano anterior como ano de referência, mas reconhece que as despesas do governo podem ser negativamente correlacionadas com o PIB, por efeito dos estabilizadores automáticos como o seguro-desemprego. Similarmente, as receitas podem positivamente ser correlacionadas com o PIB, por exemplo, devido à progressividade do sistema tributário. Por ambas as razões, o déficit tende a se elevar endogenamente durante um período de recessão. Blanchard sugere estimar

L. A. T. \& SACHSIDA, A. Avaliando a Condição da Política Fiscal no Brasil. Revista de Economia e Administração, Vol. 9 No. 3 (2010): 294-316.

${ }^{64}$ JAROCINSKI, M. \& SMETS, F. House Prices and the Stance of Monetary Policy. Monetary Policy Under Uncertain - 32 $2^{\text {nd }}$ Annual Economic Policy Conference of the Federal Reserve. Federal Reserve Bank of St. Louis, 2007. Uma versão do trabalho se encontra disponível em: http://www.ecb.europa.eu/pub/pdf/ scpwps/ecbwp891.pdf

${ }^{65}$ BLANCHARD. Suggestions For a New Set of Fiscal Indicators. 
quais seriam as despesas e receitas correntes do governo se a taxa de desemprego tivesse permanecido a mesma do ano anterior.

Nós aqui tomamos outro itinerário. Partimos da ideia de que, a fim de conhecer a condição da política fiscal, precisamos determinar o impacto dos instrumentos de política fiscal sobre variáveis chave ${ }^{66}$ da economia, que podem ser o produto ou a inflação. O comportamento dessas variáveis envolveria implicitamente os objetivos de política econômica. Em geral, essa abordagem envolve o desenvolvimento de algum tipo de indicador que sumarize o estado de política fiscal. A princípio, isso pode ser feito usando um índice definido pela soma ponderada das variações na despesa pública e na receita correntes em relação a um ano-base. Isso refletiria o impacto relativo destes instrumentos da política fiscal sobre uma variável objetivo, tal como produto da economia ou a taxa de inflação.

O nosso indicador da condição fiscal, denominado aqui Índice Condição Fiscal (ICF), pode ser obtido a partir do modelo de projeção condicional desenvolvido por Thomas Doan, Robert Litterman e Christopher Sims ${ }^{67}$ e por Daniel T. Waggoner e Tao Zha ${ }^{68}$ a partir dos coeficientes estimados de um vetor autorregressivo (VAR) ${ }^{69}$.

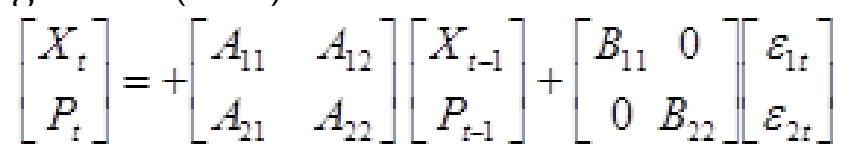

onde $X_{t}$ é o vetor de variáveis de estado (não política) e $P_{t}$ é o vetor das variáveis de política.

${ }^{66}$ Variáveis que o policy marker deve exercer algum controle mais direto.

${ }^{67}$ DOAN, T. ; LITTERMAN, R. B. \& SIMS, C. Forecasting and Conditional Projection Using Realistic Prior Distributions. Econometric Review, Vol. 3 (1984): 1-100

${ }^{68}$ WAGGONER, D. F. \& ZHA, T. Conditional Forecasts in Dynamic Multivariate Models. Review of Economics and Statistics, Vol. 81, No. 4 (1999): 639-651.

${ }^{69}$ Para uma análise mais aprofundada sobre VAR, consultar: HAMILTON, J. D. Time Series Analysis. Princeton: Princeton University Press, 1993; ENDERS, W. Applied Econometric Time Series. New York: John Wiley and Sons, 1995.
De acordo com Waggoner e Zha, "quando se impõem restrições sobre os valores futuros de uma variável endógena, a variável deve continuar a ser tratada como endógena durante os períodos futuros"70. A previsão sob tal circunstância é denominada previsão condicional ${ }^{71}$. A teoria associada à previsão condicional apareceu originalmente no artigo de Doan, Litterman, e Sims, no qual mostraram como implementar este método num modelo $\mathrm{VAR}^{72}$. Usando a teoria da previsão condicional, pode-se ver que a estrutura de erro de previsão da variável objetivo também está sob o efeito da condição da política, que agora responde endogenamente ao estado da economia. Este novo indicador é definido da seguinte forma: $I C F=S_{j} \sum_{s=1}^{T} A_{11}^{s-1} A_{12}\left(P_{t-s}-P_{t-s}^{*}\right)+S_{j} \sum_{s=1}^{T} A_{11}^{s-1} B_{11}\left(E\left[\varepsilon_{1 t-s} \mid P\right]-E\left[\varepsilon_{1 t-s} \mid P_{t-s}^{*}\right]\right)$

Este indicador mede a condição da política fiscal como sendo a diferença entre os valores preditos da variável objetivo em relação aos valores observados e de estado estacionário dos instrumentos de política fiscal. A primeira parte da expressão (6) é a mesma que aparece no índice dinâmico ID - equação (5)- mas agora o efeito de um choque na variável objetivo está condicionado à trajetória predita para os instrumentos de política. Mais especificamente, os erros de previsão são gerados a partir de uma distribuição condicional, cuja restrição é imposta pela trajetória futura assumida para as variáveis de política.

70 WAGGONER \& ZHA. Conditional Forecasts in Dynamic Multivariate Models.

71 Denomina-se previsão incondicional o caso em que não ocorre restrição sobre a trajetória futura de certas variáveis futuras ou nos erros de previsões incondicionais na literatura da previsão. Uma explicação interessante acerca do método de previsão condicional aparece em: ROBERTSON, J. C. \& TALLMAN, E. Vector Autoregressions: Forecasting and Reality. Economic Review, First Quarter, FED of Atlanta, 1999.

72 DOAN, T. ; LITTERMAN, R. B. \& SIMS, C. Forecasting and Conditional Projection Using Realistic Prior Distributions. 
Os artigos de Doan, Litterman e $\operatorname{Sims}^{73}$ e de Waggoner e Zha ${ }^{74}$ mostraram que a média dessa distribuição condicional é dada por:

$$
\varepsilon_{1}^{*}=R^{\prime}\left(R R^{\prime}\right)^{-1}(P-E[P])
$$

onde $\varepsilon_{1}^{*}$ é o único vetor para o erro de previsão, empilhado sobre o horizonte de período $T$, e que satisfaz a restrição e minimiza a soma dos erros quadráticos $\varepsilon^{\prime} \varepsilon ; R$ é a matriz dos coeficientes empilhados da função de resposta impulso, tendo em vista que $P-E[P]$ é o vetor correspondente aos valores empilhados dos erros de previsão.

\section{IV.4 - Resultados 1}

De modo a levar a cabo a nossa proposta de usar o ICF para avaliar a condição da política fiscal, é necessário inicialmente estimar um VAR e daí empregar o método de previsão condicional. Os valores de estado estacionário são calculados como os valores do equilíbrio do VAR. Este vetor foi estimado usando dados mensais do governo central trimestrais para o período entre janeiro de 1997 a março de 2012, com base no seguinte conjunto de variáveis macroeconômicas ${ }^{75}$ : hiato do produto, taxa de inflação, taxa nominal de juros, despesas públicas correntes e carga tributária líquida ${ }^{76}$.

\footnotetext{
${ }^{73}$ Idem, Ibidem.

74 WAGGONER \& ZHA. Conditional Forecasts in Dynamic Multivariate Models.
}

${ }^{75}$ Os gráficos das séries são mostrados no apêndice C.

${ }^{76}$ Os critérios de informação de Schwarz e de HannanQuinn sobre a ordem de defasagem do VAR sugerem um modelo com duas defasagens, enquanto os critérios de erro de predição final (final prediction error- FPE) e de razão de verossimilhança (likelihood ratio- LR), um VAR com uma defasagem. Usamos aqui o VAR com duas defasagens. Em seguida à estimação do modelo, verificamos a condição da estabilidade do VAR e observou-se que todos os valores próprios se encontram dentro do círculo de unitário. Isso implica que o nosso VAR satisfaz a condição de estabilidade. Assim, foi possível obter os valores de estado estacionário (SS) ou de equilíbrio tal como é mostrado na Tabela 1. Realizamos também os testes de especificação para os resíduos que incluem os teste de White para
A escolha das variáveis foi baseada nos diversos estudos mais recentes que aparecem na literatura e que empregam modelo VAR para análise da política fiscal ${ }^{77}$. As séries foram sazonalmente ajustadas. A definição precisa e as fontes são as seguintes:

HIATO: define a diferença entre o log do valor observado do PIB dessazonalizado e seu nível potencial. O PIB potencial foi estimado pelo filtro de Hodrick-Prescott. Fonte: Banco Central do Brasil - (BCB);

INFLAÇÃO: a taxa de inflação é definida por $\log \left(I P C A_{t} / I P C A_{t-1}\right)$, onde IPC $A_{t}$ é o Índice de Preços ao Consumidor Amplo no mês $t$. Fonte: IBGE;

SELIC: é a média trimestral da taxa nominal de juros de curto prazo estabelecida pelo Banco Central do Brasil (BCB). Fonte: BCB; DESPESA: relação entre os gastos correntes do governo geral e o PIB. Os gastos correntes incluem despesas totais com servidores públicos e encargos sociais mais outras despesas de consumo e de capital. Fontes: STN; RECEITA: relação entre a receita pública líquida de impostos e o PIB. A receita líquida é definida como receita bruta menos as seguintes variáveis: seguro-desemprego, Fundo de Amparo ao Trabalhador (FAT), subsídios e juros líquidos sobre a dívida pública. Fonte: IPEA.

Neste estudo, as variáveis RECEITA e DESPESA são tomadas como os instru-

heteroscedasticidade, o teste do multiplicador de Lagrange para autocorrelação assim como os testes de Jarque-Bera, curtose e assimetria para checar a hipótese de normalidade. Para todos os testes não encontramos nenhum problema mais sério de especificação.

${ }^{77}$ FATÁS, A. \& MIHOV, I. Fiscal Policy and Business Cycles: An Empirical Investigation. Moneda y Credito, Vol. 211 (2000); BLANCHARD, O. Suggestions For a New Set of Fiscal Indicators. OECD Economics and Statistics Department, Working Paper, No. 79 (1993).; ALESINA, A.; PEROTTI, R. Fiscal Adjustments in OECD countries: composition and macroeconomic effects. Washington: International Monetary Fund - (IMF), Working Paper, No. 96/70 (1997); MOUNTFORD, A. \& UHLIG, H. What are the Effects of Fiscal Policy Shocks? Berlin: Humboldt University, 2005. (Discussion Paper 039). 
Figura 1 - Hiato condicionado ao gasto e à receita

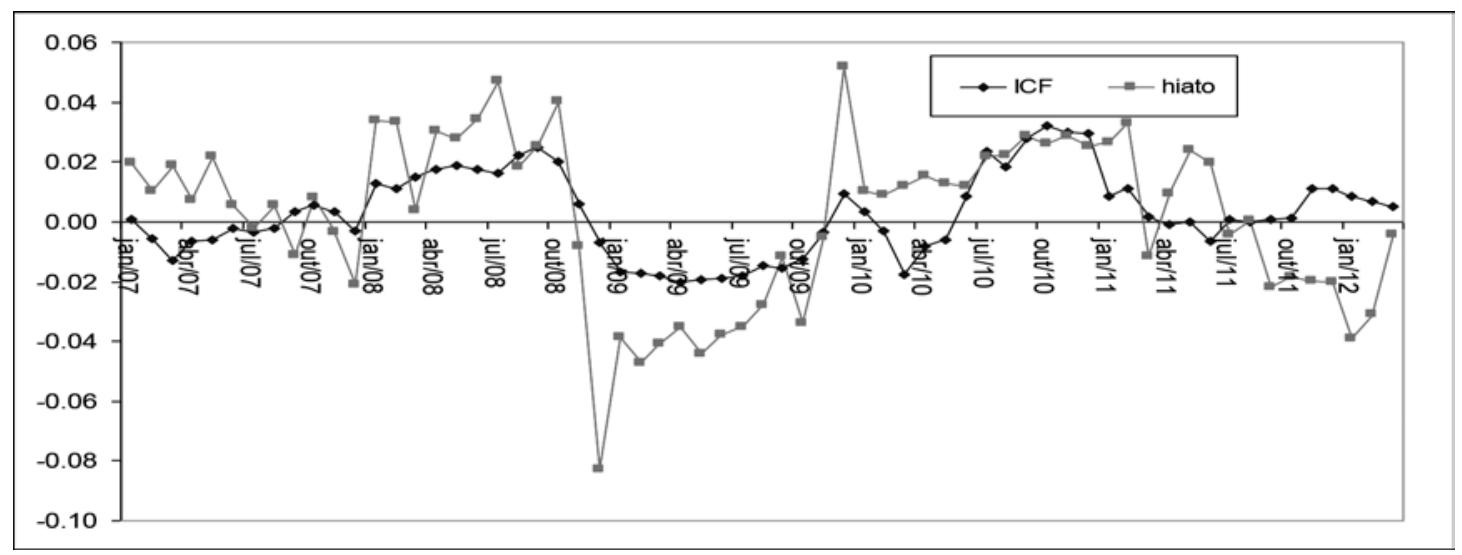

Figura 2 - Hiato condicionado ao gasto corrente

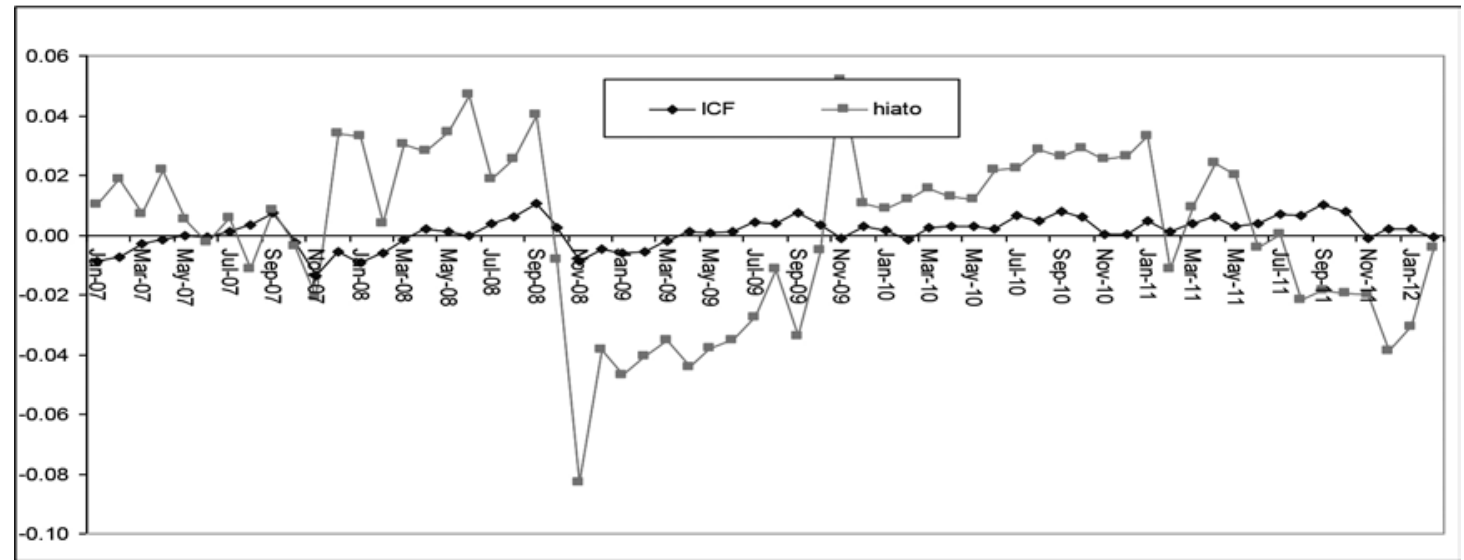

mentos de política fiscal ${ }^{78}$. A Figura 1 mostra o ICF tomando como variável meta o hiato do produto $^{79}$ em relação ao nível de tendência ${ }^{80}$ calculado para o período 1997-2012 ${ }^{81}$. Valores do ICF positivos indicam que a política fiscal é expansiva enquanto valores negativos indicam

${ }^{78}$ A escolha dos instrumentos de política fiscal está em concordância com os estudos que fazem uso do modelo VAR para análise da política fiscal. Ver: FATÁS, A. \& MIHOV, I. Fiscal Policy and Business Cycles; BLANCHARD. Suggestions For a New Set of Fiscal Indicators; MOUNTFORD, A. \& UHLIG, H. What are the Effects of Fiscal Policy Shocks?.

${ }^{79}$ Pelo fato de o PIB ser uma variável não estacionária, não seria possível obter o valor de equilíbrio para esta variável. Outra possível saída se daria pelo uso do PIB nas diferenças, o que ocasionaria forte perda de informação relevante.

${ }^{80}$ Valor referente ao de estado estacionário.

${ }^{81}$ Para melhor visualização e por economia, mostramos no gráfico o comportamento do índice a partir de 2007. que a política fiscal é restritiva. Como pode ser visto, a Figura 1 mostra que a política fiscal tem sido expansiva na maior parte do período no que se refere ao seu efeito sobre o produto. Notemos ainda que a partir de julho de 2011, o ICF mostra que a política fiscal além de ser expansionista se mostra também como anticíclica. O ICF foi também calculado como o objetivo de ver apenas o efeito do gasto corrente do governo. A Figura 2 apresenta o ICF condicionado somente ao gasto. De acordo com essa figura, considerando apenas o gasto corrente como instrumento de política, a política fiscal foi expansiva na maior parte do período, sobretudo a partir de março de 2010, não importando se seu comportamento se mostrava pró ou anticíclico. Entretanto, visto que o hiato do produto desde junho de 2011 se mostrou negativo, apresentando uma queda acentuada, podemos notar que a política fiscal continuou a ser expansiva. 


\section{IV.5 - Efeito de um choque monetário sobre a construção civil}

$\mathrm{Na}$ seção anterior mostramos que a política fiscal no Brasil tem tido um viés mais expansionista, pelo menos no período mais recente desde 2007. Isso significa que é possível que o efeito dos gastos do governo esteja impactando sobre o crescimento da inflação. Assim, é possível que o governo em algum momento use seu instrumento de política monetária mais eficaz, a taxa de juros, como meio de controlar a inflação. $\mathrm{O}$ aumento da taxa de juros poderá ter efeito bastante danoso sobre o mercado imobiliário. Grande parte das transações no setor imobiliário no Brasil assim como em outros países são feitos com base em contratos de financiamento de longo prazo regidos por taxas de juros pós-fixadas. Também uma elevação da taxa de juros faz com que o lucro projetado do empreendimento seja menor, inviabilizando muitos projetos. Nesse sentido, esta seção tem como propósito detectar o efeito de um choque de política monetária sobre variáveis fundamentais associadas ao setor imobiliário como a construção civil e o crédito imobiliário por meio do modelo VAR estrutural (SVAR) ${ }^{82}$. Uma ampla literatura sobre modelos de VAR estrutural tem sido aplicada para se analisar os efeitos de choques monetários na economia assim como em estudos acerca do efeito da política fiscal. Contudo, esta metodologia também tem sido empregada para verificar o efeito de choque de um choque de política monetária sobre o mercado imobiliário ${ }^{83}$.

\footnotetext{
${ }^{82}$ Para maiores detalhes sobre a modelo VAR pode ser encontrado em: SIMS, C. Are Forecasting Models Usable for Policy Analysis? Federal Reserve Bank of Minneapolis Quarterly Review, Vol. 10 No. 1 (Winter 1986): 1-16; FACKLER, P. Vector Autoregressive Techniques for Structural Analysis. Revista de Analisis Econômico, Vol. 3, No. 2 (1988): 119-34; HAMILTON. Time Series Analysis; ENDERS. Applied Econometric Time Series.

${ }^{83}$ A valorização do patrimônio residencial já possuído estimula o investimento em outro de padrão superior. Ver os seguintes estudos: KAHN, G. A. The Changing
}

\section{IV.6 - VAR Estrutural (SVAR)}

O VAR estrutural (SVAR) pode ser representado da seguinte maneira:

$$
A Y_{t}=\alpha+\sum_{i=1}^{p} A_{i} Y_{t-i}+\varepsilon_{t} \text { para } t=0: T,
$$

Se assumirmos que $A$ é inversível, então (1) tem a forma reduzida dada por:

$$
Y_{t}=\beta+\sum_{i=1}^{p} B_{i} Y_{t-i}+u_{t}
$$

com $u_{t} \sim N(0, \Sigma)$ e $E\left(u_{t} u_{s}^{\prime}\right)=0, \forall t \neq s$, onde $u_{t}$ é a forma reduzida dos resíduos e $b$ é um vetor

de constantes. Assumimos que $\varepsilon_{t} \sim N(0, I)$. A relação entre os modelos (1) e (2) é baseada nas seguintes equações:

$$
\begin{gathered}
\beta=A^{-1} \alpha, B_{i}=A^{-1} A_{i}, u_{t}=A^{-1} \varepsilon_{t}, \mathrm{e} \\
\Sigma=A^{-1} E\left(\varepsilon_{t} \varepsilon_{t}^{\prime}\right)\left(A^{-1}\right)^{\prime}=A^{-1}\left(A^{-1}\right)^{\prime} .
\end{gathered}
$$

Note que tal representação não permite a identificação de choques exógenos independentes nas variáveis, isso ocorre pois os resíduos das formas reduzidas são contemporaneamente correlacionados (a matriz S é não diagonal ${ }^{84}$. Isto é, os resíduos da forma reduzida $u_{t}$ podem ser interpretados como resultado de uma combinação linear de choques exógenos que não são correlacionados contemporaneamente. Não é possível distinguir qual o choque que afeta determinada variável na forma reduzida. Para a avaliação

Interest Sensitivity of the U. S. Economy. Economic Review, November (1989):13-34; POZDENA, R. J. Do Interest Rates Still Affect Housing? Economic Review, Federal Reserve Bank of San Francisco (Summer 1990): 3-14; RYDING, J. Housing Finance and the Transmission of Monetary Policy. Quarterly Review, Federal Reserve Bank of New York (Summer 1990); McCARTHY, J. \& PEACH. R. W. Monetary Policy Transmission to Residential Investiment. Economic Policy Review, Federal Reserve Bank of New York, (2002): 139-58; MISHKIN, F. S. Housing and Monetary Transmission Mechanism. NBER, October 2007 (Working Paper, No. 13518).

${ }^{84}$ Tais choques são forças primitivas e exógenas, sem causa comum, que afetam as variáveis do modelo. 
de política somente faz sentido verificar o efeito de um choque independente. É possível estimar os parâmetros $B$ e $\Sigma$ em (2) de maneira consistente mas, exceto para previsão, eles não são parâmetros de interesse. Sem restrições adicionais em A nós não podemos recuperar a forma estrutural a partir da forma reduzida, pois $\Sigma$ não possui coeficientes estimados em número suficiente para se recuperar a matriz não-restrita A. Dessa maneira, precisamos impor um número de restrições que tornem possível a identificação e estimação de A. Este procedimento é conhecido por identificação.

A matriz A pode ser estimada por meio das informações presentes na matriz de covariância da forma reduzida. O ponto importante aqui é que, geralmente, existe um grande número de matrizes de posto completo $A$ que nos permite reproduzir $\hat{\Sigma}$. Isto é, existem várias condições de dependência e independência nas correlações contemporâneas (Núcleos de Markov ${ }^{85}$ ) entre as variáveis - dadas pelas diferentes especificações onde os parâmetros em $A$ são livres ou restritos igual a zero - que nos permitem reproduzir as correlações parciais observadas dos resíduos na forma reduzida ${ }^{86}$. Isso significa que $A^{-1}\left(A^{-1}\right)^{\prime}=\widetilde{A}^{-1}\left(\widetilde{A}^{-1}\right)^{\prime}$ onde $\widetilde{A}$ é a decomposição

${ }^{85}$ Markov Kernels.

${ }^{86}$ A matriz $A$ não pode ter, em seu conjunto, um número de parâmetros livres maior do que o número de parâmetros livres na matriz simétrica. Se $\mathrm{n}$ for o número de variáveis endogenas do modelo então, para satisfer à condição da ordem para a identificação de $\mathrm{A}$, é necessário que o número de parâmetros livres a ser estimado em A seja não maior do que n(n1)/2. Quando n é menor do que $n(n-1) / 2$ o modelo é sobre- identificado. Não existe uma condição geral simples para a identificação local dos parâmetros de A. Como foi mostrado por Thomas J. Rothenberg (1971), uma condição necessária e suficiente para a identificação local de algum ponto regular no $\mathrm{R}^{\mathrm{n}}$ é que a determinante da matriz da informação seja diferente de zero. Na prática, as avaliações da determinante da matriz da informação em alguns pontos, escolhida aleatoriamente no espaço dos parâmetros, são o bastante para estabelecer a identificação de um determinado modelo. Ver: ROTHENBERG, Thomas J. Identification in Parametric Models. Econometrica, Vol. 39, No. 3 (May, 1971): 577-91. de Choleski para $\hat{\Sigma}$. Resumindo, existem várias maneiras de se decompor $\hat{\Sigma}$.

Para se estimar um modelo estrutural é necessário identificar um número de relações condicionais independentes (istoé, parâmetros iguais a zero em $A_{0}$ ) para satisfazer a condição de ordem para identificação. Dessa maneira, identificar $A$ é equivalente a identificar a distribuição condicional ("Markov Kernels") dos resíduos da forma reduzida das informações sobre suas distribuições conjuntas. O procedimento de identificação determina a ordem de causalidade entre as variáveis endógenas do VAR estrutural. De acordo com Harald Uhlig a identificação é feita usualmente seguindo-se um dos três seguintes métodos ${ }^{87}$ : i) aplicando-se a decomposição de Cholesky na matriz de covariância dos resíduos $S$ o que implica num ordenamento recursivo ${ }^{88}$. Impor alguma relação estrutural na matriz $A^{89}$, ou separando impulsos transitórios de permanentes nos impulsos primários $\varepsilon_{t}{ }^{90}$.

\section{IV.7 - Resultados 2}

Infelizmente, como já colocamos, não dispomos de variáveis fundamentais para o mercado imobiliário como índices de preço e de produto específicos para esse setor. Contudo, temos o produto industrial da construção civil $^{91}$ (INDCC) que pode servir como uma proxy para a produção no setor imobiliário. Outra importante variável incluída é o fluxo de crédito de financiamento imobiliário (FCRED). Tendo em vista que a maior parte dos recursos

${ }^{87}$ UHLIG, H. What are the Effects of Monetary Policy on Output? Results from an Agnostic Identification Procedure. Journal of Monetary Economics, 52 (2005): 381-419.

${ }^{88}$ SIMS. Are Forecasting Models Usable for Policy Analysis?

89 BERNANKE, B. Alternative Explanations of the Money-Income Correlation. Carnegie-Rochester Conference Series on Public Policy, 25 (1986): p. 49-100.

90 BLANCHARD \& WATSON. Bubbles, Rational Expectations and Financial Markets.

${ }^{91}$ Insumos. 
para financiamento imobiliário no Brasil deriva de crédito direcionado pelo governo, pode-se então assumir que a oferta de crédito é exógena. Portanto o efeito de um choque monetário sobre a variável FCRED deve ser entendido como um efeito sobre a demanda por financiamento imobiliário. Incluímos ainda o gasto corrente do governo (GASTO), pois a expansão do setor imobiliário atualmente acontece como consequência de obras públicas para atender a demanda dos eventos internacionais de 2014 e 2016. As demais variáveis no nosso VAR como o índice de inflação (INFLA), o produto real da economia (PIB) e a taxa nominal de juros de curto prazo (SELIC) seguem de perto outros trabalhos existentes na literatura sobre impacto da política monetária no Brasil e que fazem uso do modelo $\mathrm{SVAR}^{92}$. O período analisado foi de junho de 2000 a dezembro de $2011^{93}$.

PIB: é o produto real mensal, ajustado sazonalmente e deflacionado - fontes: Instituto Brasileiro de Geografia e Estatística (IBGE) e BCB;

INFLA: a taxa de inflação é definida por $\log \left(I P C A_{t} / I P C A_{t-1}\right)$, onde $I P C A_{t}$ é o Índice de Preços ao Consumidor Amplo no mês t. Fonte: IBGE;

SELIC: é a taxa de juros mensal nominal de curto prazo (fonte: $\mathrm{BCB}$ );

GASTO: gastos correntes do governo geral. Os gastos correntes incluem despesas totais com servidores públicos e encargos sociais mais outras despesas de consumo e de capital. Fontes: STN;

${ }^{92}$ MINELLA, A. Monetary Policy and Inflation in Brazil (1975-2000): a VAR Estimation. Revista Brasileira de Economia, Vol. 57, No. 3 (2003): 605-35; CÉSPEDES, B. ; LIMA, E. ; MAKA, A. \& MENDONÇA, M. J. Measuring Monetary Policy Stance in Brazil; CÉSPEDES, B. ; LIMA, E. \& MAKA, A. Monetary Policy, Inflation and the Level of Economic Activity in Brazil after the Real Plan: Stylized Facts from SVAR Models. Revista Brasileira de Economia, Vol. 62, No. 2 (abr./jun. 2008): 123-160; MENDONÇA, M. J. ; MEDRANO, L. A. T. \& SACHSIDA, A. Efeitos da Política Monetária na Economia Brasileira: Resultados de um Procedimento de Identificação Agnóstica. Pesquisa e Planejamento Econômico, Vol. 40, No. 3 (2010): 367-94.

${ }^{93}$ Dados sobre o fluxo de crédito imobiliário estão disponíveis somente a partir de 2000.
INDCC: produto industrial da construção civil (fonte: IBGE);

FCRED: fluxo crédito habitacional ao setor privado deflacionado pelo IPCA (fonte: $\mathrm{BCB}$ ).

A identificação do VAR estrutural se deu a partir do emprego do método de gráficos acíclicos dirigidos (GADs) ${ }^{94}$ para determinar a ordenação de causalidade contemporânea do $\mathrm{SVAR}^{95}$. Usando as ordenações selecionadas para identificar o SVAR, pode-se então gerar as funções de resposta do impulso (IRFs). Os GADs foram estimados pelo programa TETRAD ao nível de significância ${ }^{96} 0.5 \%$ na matriz de covariância dos resíduos e assumindo a hipótese de que as variáveis selecionadas para o modelo são causal suficientes ${ }^{97}$, obtemos o que se denomina padrão. $\mathrm{O}$ padrão aqui é definido como uma representação gráfica de um conjunto de GADs que contêm

${ }^{94}$ Seguindo o estudo de Norman Swanson e Clive Granger, o trabalho de Brisne Céspedes, Elcyon Lima e Alexis Maka adota a abordagem de GADs para inferir as relações causais contemporâneas entre um conjunto de variáveis macroeconômicas considerando também as alterações da política monetária ocorridas após o Plano Real. Ver: CÉSPEDES ; LIMA \& MAKA. Monetary Policy, Inflation and the Level of Economic Activity in Brazil after the Real Plan: Stylized Facts from SVAR Models. Ver, também: SWANSON, N. \& GRANGER, C. Impulse Response Functions Based on a Causal Approach to Residual Orthogonalization in Vector Autoregressions. Journal of the American Statistical Association, Vol. 92, No. 437 (1997): 357-67.

95 SPIRTES, P. ; GLYMOUR, C. \& SCHEINES, R. Causation, Prediction, and Search. Cambridge: MIT Press, $2^{\text {nd }}$ ed., 2000.

${ }^{96} \mathrm{O}$ nível de significância não pode ser interpetrado como a probabilidade do erro do tipo 1, mas apenas um parâmetro de busca. Baseado em simulações para DAGs geradas estocasticamente, SGS sugere um nível de significância de $20 \%$ para amostras de tamanho menor que 100; $10 \%$ para amostras de tamanho entre 100 e 300; e 10\% (ou menor) para amostras maiores.

${ }^{97} \mathrm{Um}$ conjunto $V$ de variáveis é dito causal suficiente se qualquer causa comum de duas ou mais variáveis em $V$ está em $V$. O TETRAD tem um viés para exclusão de relação causal presente no dado. De modo a contornar essa limitação, o programa sugere que um nível de significância de $20 \%$ deve ser usado. 
as relações de causalidade contemporânea das variáveis. O GADs detectaram cinco ${ }^{98}$ representações válidas de causalidade contemporânea. As relações derivadas do GADs entram em $A_{0}$ como restrições que ajudam no processo de identificação dessa matriz tal como definido acima. No apêndice $\mathrm{A}$, mostramos como aplicar a ordenação causal obtida do GADs para identificar a matriz $A_{0}$.

A estimação do VAR foi feita com duas defasagens tendo em vista os critérios de informação de Schwarz e Hannan-Quinn. As funções de impulso-resposta de um choque monetário contracionista representado por um aumento inesperado da SELIC do tamanho de um desvio-padrão para um horizonte de tempo 48 meses são mostrados na Figura 3. Com exceção da SELIC e da taxa de inflação, as demais foram tomadas em logaritmo.

De acordo com os resultados podemos fazer as seguintes afirmações. Com relação aos resultados específicos relativos ao mercado imobiliário, um choque contracionista de política monetária produz os seguintes efeitos. Observa-se que o crédito imobiliário assim como o produto industrial da construção civil registram quedas acentuadas. Podemos ver ainda que com quase $100 \%$ de probabilidade que as variáveis FCRED e INDCC apresentam queda imediatamente após o choque, demonstrando ainda forte persistência em relação à média durante todo o horizonte temporal. A demanda por crédito se retrai visto que a propensão de demandar novos contratos de hipoteca por parte dos mutuários diminui. Assim, esse resultado mostra que de fato um aumento da taxa de juros tem forte impacto sobre o mercado imobiliário via o mercado de crédito. A retração na demanda por crédito tem efeito sobre o produto da construção, pois naturalmente menor será a demanda por novas unidades habitacionais. Com relação às demais variáveis como o gasto corrente do governo, PIB e a inflação podemos tecer os

98 Os GADs encontraram as seguintes ordens de causalidade: SELIC $\leftrightarrow P I B, S E L I C \leftrightarrow$ FCRED, INFLA $\rightarrow$ SELIC, INDCC $\rightarrow$ PIB e INDCC $\rightarrow$ FCRED. seguintes comentários. Na média, o PIB real reage de forma negativa choque monetário. Pode ser visto que a maior parte do intervalo de confiança está fortemente concentrada em valores negativos até o décimo quinto mês. No que se refere ao gasto do governo, nota-se que o efeito de uma contração monetária sobre essa variável tende a se concentrar no lado mais sobre a banda negativa do intervalo de confiança da IRF.

Por fim, o ponto mais preocupante aqui é a verificação a ocorrência do chamado enigma do preço (price puzzle), isto é, uma resposta positiva do índice de preço com relação ao choque monetário. De acordo com alguns economistas o enigma do preço acontece quando o VAR está mal especificado $^{99}$. Contudo, essa visão não é unânime na literatura. Existe uma explicação alternativa segundo a qual um choque transitório negativo de oferta teria o efeito de aumentar a taxa de juros real, diminuindo o produto e provocando a subida do nível de preços pelo menos no curto prazo. A autoridade monetária responde ao choque adverso de oferta subindo a taxa de juros, mas não o suficiente para extinguir as consequências inflacionárias deste. Além disso, pode-se argumentar ainda que diferentemente do que coloca corrente tradicional, é o canal de custo da política monetária que faz com que os preços e a taxa

99 Christopher Sims atesta que o enigma do preço (price puzzle) ocorre pelo fato que o modelo SVAR não estimam corretamente o componente forward-looking da política monetária e, portanto não avaliam de forma apropriada o choque de política monetária. Suponha que o banco central espera uma inflação mais elevada no futuro. Quando o banco central aumenta a taxa de juros, este choque já estaria exercendo efeito sobre a economia de modo que um aumento simultâneo da taxa de juros e dos preços é observado. Consequentemente, o enigma do preço ocorreria devido à má especificação do componente forward-looking da política monetária. Sims sugeriu que uma vez que os preços das matériasprimas sejam incluídos em um modelo do VAR, o "price puzzle" desapareceria. Ver: SIMS, C. Interpreting the Macroeconomic Time Series Facts: The Effects of Monetary Policy. European Economic Review, Vol. 36, No. 5 (1992): 975-1000. 
Response to Structural One S.D. Innovations \pm 2 S.E.
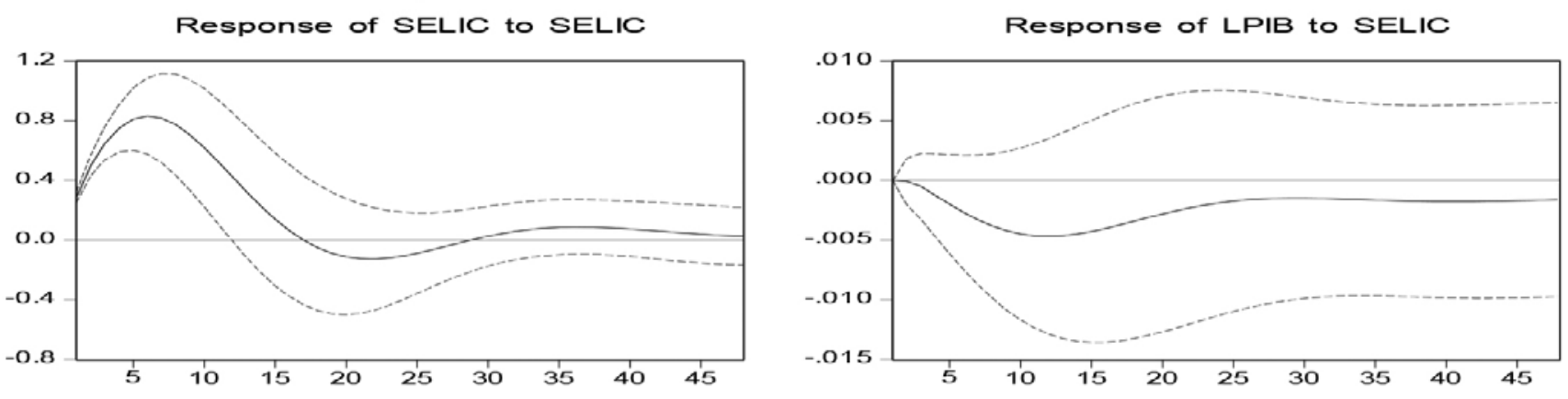

Response of LINDCC to SELIC
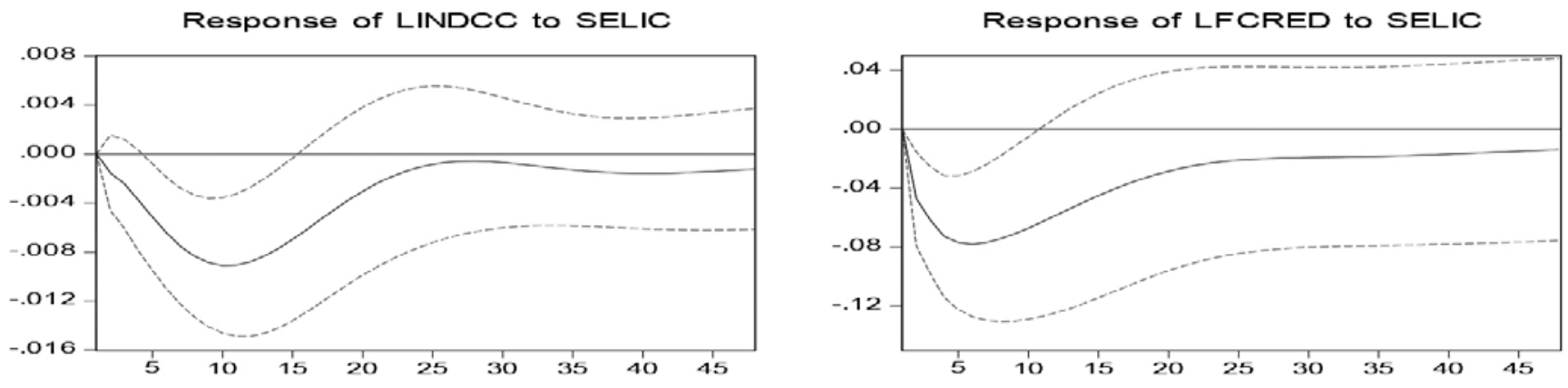

Response of INFLA to SELIC
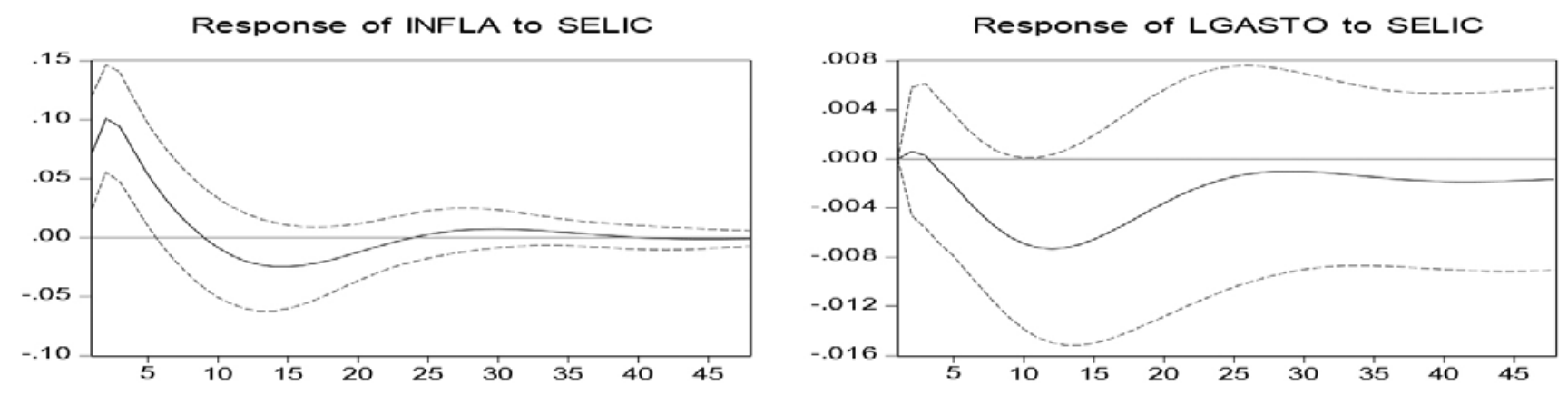

de juros nominal reajam na mesma direção depois de um choque de política monetária. Quando o Banco Central eleva a taxa de juros alguns custos aumentam, tendendo a causar um aumento na taxa de inflação. Este efeito do lado da oferta pode coexistir e dominar o tradicional efeito do lado da demanda ${ }^{100}$.

\section{Comentários Finais}

Este trabalho estudou e empregou diversas metodologias, tanto a nível microeco-

100 RABANAL, P. Does Inflation Increase After a Monetary Policy Tightening? Answers Based on an Estimated DSGE Model. Journal of Economic Dynamics and Control, 31: (March 2007): 906-37.

nômico quanto a nível macroeconômico, para verificar a possibilidade de existência de uma bolha no mercado imobiliário brasileiro. De maneira geral, todos os resultados apontam para a possibilidade concreta de existência de uma bolha no mercado de imóveis no Brasil. De maneira extremamente objetiva, a Teoria Austríaca do Ciclo Econômico fornece uma base teórica sólida para apontarmos o governo federal, por meio de suas políticas fiscais e de estímulo ao crédito, como o principal responsável pelo surgimento dessa bolha. A insistência do governo em aquecer ainda mais um mercado imobiliário já aquecido só tende a piorar o resultado final.

Deve-se ressaltar também que a esmagadora maioria dos contratos de financiamento 
habitacional no Brasil é feito com juros pós-fixados. Além disso, tal como os resultados da parte econométrica deste estudo sugerem, o mercado imobiliário é sensível e responde negativamente a um aumento nas taxas de juros. Isto é, aumentos nas taxas de juros podem trazer significativos problemas ao mercado imobiliário. Ressaltamos ainda que foi justamente o aumento nas taxas de juros, provocadas pelo Banco Central Americano, o gatilho que ocasionou a explosão da bolha imobiliária nos Estados Unidos em 2007 e 2008.

Insistimos em ressaltar que as atuais políticas fiscais e monetárias do governo brasileiro são claramente inflacionárias. Tais políticas levarão inevitavelmente ao aumento do custo de vida no Brasil, e a todos os demais custos associados com o recrudescimento do processo inflacionário. Lembramos também, que as taxas de juros internacionais estão num patamar mínimo histórico. Isto quer dizer que, cedo ou tarde, as taxas de juros internacionais irão subir. Quando isso ocorrer, o Brasil também será obrigado a aumentar a taxa de juros doméstica. Então os verdadeiros custos, associados com as políticas fiscais e monetárias expansionistas adotadas pelo governo Brasileiro, irão aparecer.

Naturalmente, não acreditamos que uma crise no mercado imobiliário brasileiro, caso aconteça, irá ter efeito catastrófico como ocorreu no caso dos Estados Unidos e em alguns países da Europa, até mesmo pelo fato de que a oferta de crédito no Brasil é ainda bastante restrita. Contudo, não serão desprezíveis. Quando o governo brasileiro for obrigado a aumentar a taxa de juros doméstica teremos um impacto direto dessa medida no setor imobiliário. E então será a vez do Brasil lidar com sua crise. Crise essa criada exclusivamente pelo mau gerenciamento das políticas fiscais e monetárias do governo brasileiro. Não terá sido o mercado o criador da crise, mas sim o governo do Brasil.

Para finalizar, quando esse desastre ocorrer o governo irá procurar culpados. Irá culpar a todos, exceto sua falta de responsabilidade fiscal e monetária. O Brasil deveria aproveitar o atual bom momento da economia internacional para fazer os necessários ajustes de que esse país precisa. Contudo, esse momento esta passando e a oportunidade está sendo desperdiçada. Quando a crise surgir, o governo dará uma resposta errada. Irá aumentar ainda mais os gastos, tornando a política fiscal ainda mais expansionista, e irá facilitar ainda mais o crédito (afrouxando ainda mais o lado monetário). Essas medidas irão tornar a crise mais duradoura e mais profunda.

Quando várias pessoas erram por um tempo prolongado e em magnitudes expressivas, então existe um custo a ser pago. A interferência do governo apenas prolonga, piora, e redistribui esse custo. A interferência do governo não elimina, não faz com que o erro desapareça, apenas transfere os custos de um setor que cometeu o erro para o restante da economia. A bolha no mercado imobiliário brasileiro está sendo criada e sustentada pelo governo. Quando ela explodir o governo se proporá a corrigir, de maneira errada, uma crise que ele mesmo gerou.

\section{APÊNDICE}

\section{IDENTIFICAÇÃO DO VAR ESTRUTURAL VAR USANDO GADs}

De acordo com SGS (2003), os DGAs permitem que se estabeleçam as relações de independência condicional o que seria equivalente a determinar os coeficientes da matriz $\mathrm{A}_{0}$ que sejam iguais a zero. A teoria desenvolvida por SGS não permite descartar a possibilidade de encontrar conjuntos alternativos de relações de independência condicional. Neste caso, temos um conjunto de matrizes $\mathrm{A}_{0}$ que são equivalentes. Pode ainda ser o caso que as relações de independência condicional encontradas não sejam suficientes para permitir a identificação da matriz $\mathrm{A}_{0}$. Neste caso, restrições adicionais são necessárias a fim identificar o modelo. Vejamos um exemplo de como os GADs podem ser usados para impor restrições que permitem a identificação do VAR estrutural (SVARs). 
No exemplo abaixo o VAR tem quatro variáveis endógenas. Inicialmente, devemos ter em mente que a relação entre as formas reduzida e estrutural é dada pela seguinte equação:

$$
v_{\mathrm{t}}=\left[\mathrm{I}-\mathrm{A}_{0}\right] v_{\mathrm{t}}+\varepsilon_{\mathrm{t}}
$$

Onde: $v_{\mathrm{t}}-$ é o vetor coluna de dimensão $4 \times 1$ dos erros da forma reduzida em $t$;

FIgURA A.1

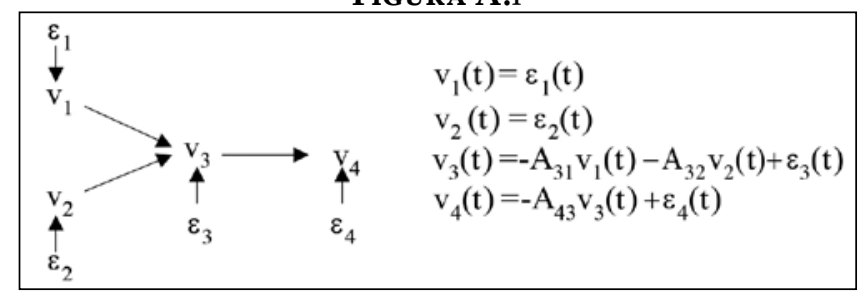

Figura A.2

$$
A_{0}=\left[\begin{array}{cccc}
1 & 0 & 0 & 0 \\
0 & 1 & 0 & 0 \\
A_{31} & A_{32} & 1 & 0 \\
0 & 0 & A_{43} & 1
\end{array}\right]
$$

$\varepsilon_{\mathrm{t}}$ - é o vetor coluna de dimensão $4 \times 1$ dos erros da forma estrutural em $\mathrm{t}$;

$\mathrm{A}_{0}$ - é a matriz de posto completo que define a relação entre os dois tipos de erros.

No exemplo acima, temos as seguintes relações identificadas pelos GADs para estabelecer quais os elementos da matriz são distintos de zero $\mathrm{A}_{0}{ }^{101}$ : A figura $\mathrm{A} 1 \mathrm{um}$ como as ordenações de causalidade são identificáças pelos GADs e como, a partir disso, obter as relações entre os erros nas formas estrutural e reduzida. A seguir, a figura A2 mostra como incluir tais relações dentro da matriz $A_{0}$.

${ }^{101} \mathrm{e}_{\mathrm{i}}$ é o termo de erro estrutural da equação i (i=1,2,3,4). 